\title{
TITLE:
}

\section{ON THE CUMACEAN CRUSTACEA FROM TANABE BAY, KII PENINSULA}

$\operatorname{AUTHOR}(\mathrm{S})$ :

Gamo, Sigeo

CITATION:

Gamo, Sigeo. ON THE CUMACEAN CRUSTACEA FROM TANABE BAY, KII PENINSULA. PUBLICATIONS OF THE SETO MARINE BIOLOGICAL LABORATORY 1962, 10(2): 153-210

\section{ISSUE DATE:}

1962-12-31

URL:

http://hdl.handle.net/2433/175314

RIGHT: 


\title{
ON THE CUMACEAN CRUSTACEA FROM TANABE BAY, KII PENINSULA ${ }^{1)}$
}

\author{
Sigeo GAMÔ \\ Faculty of Liberal Arts and Education, Yokohama \\ National University, Kamakura, Kanagawa-ken
}

With 40 Text-figures

The collection of the cumacean crustacea now dealt with was taken by towing the plankton net just below the surface at night on the 27th and 28th of May, 1959, at Tanabe Bay, near the Seto marine Biological Laboratory. In the previous paper (GAMÔ, '60b) three new species of the genus Campylaspis were proposed. Now fourteen species are named as new and additional data are given for Vaunthompsonia cristata BATE, Iphinoe sagamiensis GAMÔ, Bodotria similis CALMAN, Cyclaspis strumosa HALE, Hemilamprops californica ZIMMER and Gynodiastylis costatus CaLman etc. herein.

Before proceeding further, I must acknowledge my sincere thanks to Professor Tune SAKAI for his kind guidance. I also wish to express my heartily indebtedness to Dr. Huzio Utinomi of the Seto Marine Biological Laboratory for giving me an opportunity of performing the investigation and to Professor Masao Iw AsA of the Seikei University for his much helps and invaluable advices.

The species from Tanabe Bay are listed below:

Family Bodotriidae

Subfamily Vaunthompsoniinae HALE

Vaunthompsonia cristata BATE

Subfamily Bodotriinae HaLE

Bodotria similis CALMAN

Cyclaspis strumosa HALE

C. bidens sp. nov.

Iphinoe sagamiensis GAMÔ

Family Nannastacidae

Nannastacus japonicus sp. nov.

$N$. pruinosus sp. nov.

$N$. nudus sp. nov.

$N$. goniatus sp. nov.

1) Contributions from the Seto Marine Biological Laboratory, No. 389.

Publ. Seto Mar. Biol. Lab., X (2), 1962. (Article 10) 
$N$. nyctagineus sp. nov.

$N$. pectinatus sp. nov.

$N$. spinulosus sp. nov.

$N$. spinosus sp. nov.

Cumella glaberata sp. nov.

C. scabera sp. nov.

C. arguta sp. nov.

C. sp.

Campylaspis kiiensis GaMô

C. granulata GAMO

C. pumila GAMÔ

Family Lampropidae

Hemilamprops californica ZIMMER

Family Diastylidae

Dimorphostylis asiatica ZIMMER

D. quadriplicata GAMO

D. hirsuta GAMO

D. longicauda sp. nov.

$D$. echinata sp. nov.

Gynodiastylis costatus CALMAN

\section{Description of the Species}

\section{Family Bodotriidae}

\section{Subfamily Vaunthompsoniinae HALE}

1. Vaunthompsonia cristata BATE

(Figs. 1, 2)

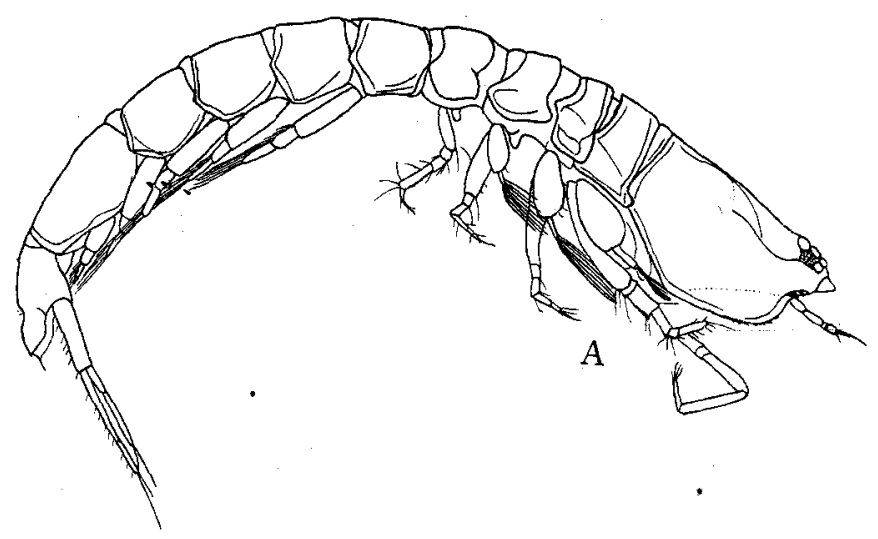

Fig. 1. Vaunthompsonia cristata BATE. Adult male (length, ca. $4.4 \mathrm{~mm}$ ). A : lateral view. 
Vaunthompsonia cristata, SARS (1879) p. 12, pls. 23-26.

V. cristata, Stebbing (1913) p. 13, figs. 5-7.

V. cristata, FAGE (1945) p. 176 ; (1951) p. 24, figs. 17-18.

V. cristata, ZIMMER (1952) p. 7, Abb. 1.

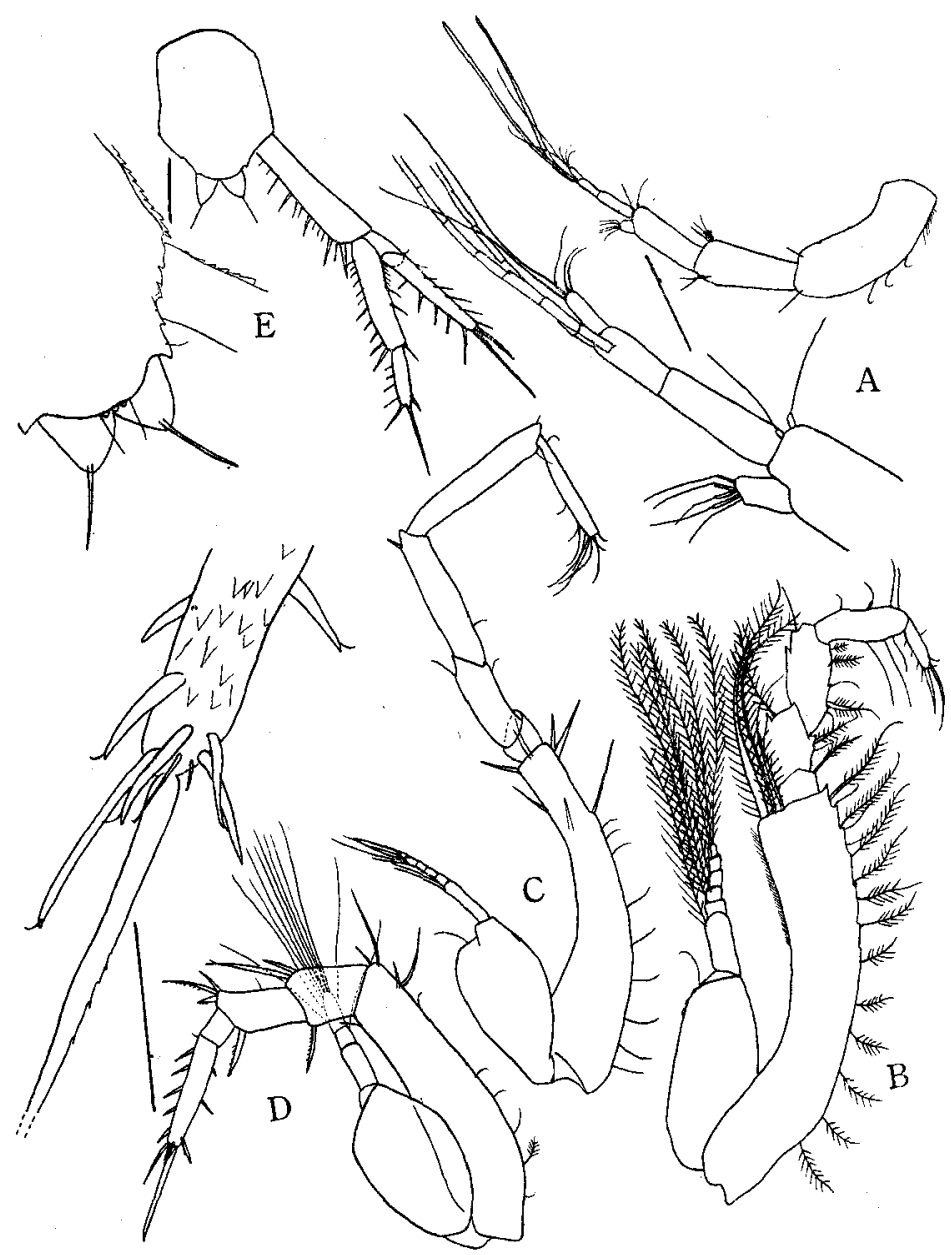

Fig. 2. Vaunthompsonia cristata BATA. Adult male. A : antennule. B : third maxilliped. C-D : first and second peraeopods. E : uropod with sixth abdominal segment.

Adult male specimen (length, about $4.4 \mathrm{~mm}$ ): The specimen differs from the description of the European specimen by having the smaller body and small serrations on the inner border of the basis of third maxilliped and of the basis of first peraeopod.

The above-mentioned differences may be due to the geographical and individual 
variations. It may also be identical with ZIMMER's description of the specimen from Indo-Chinese Seas.

Occurrence: $11 \hat{o}$.

Distribution: British Isles, West coast of France, Atlantic coast of Morocco, Mediterranean Sea and Indo-Chinese Sea.

\section{Subfamily Bodotriinae HALE}

\section{Bodotria similis CALMAN}

(Figs. 3, 4, 5)

Bodotria similis CALMAN (1907) p. 4, pl. 1, figs. 4-9.

B. siamensis CALMAN (1907) p. 5, pl. 1, figs. 10-15.

B. ? species, CaLmaN (1912) p. 609.

B. pumilio ZIMMER (1921) s. 119, Abb. 4-7.

B. similis, FAGE (1945) p. 180, fig. 6.

B. siamensis, FAGE (1945) p. 181, fig. 7 .

B. similis, KURIAN (1951) p. 81 ; (1954) p. 276.

- Ovigerous female specimen (length, about $3.1 \mathrm{~mm}$ ): The integument is calcified, rather thin and covered with finely reticulated patterns. The carapace is slightly more than one-fourth as long as the total length of animal, and one and one-third times as long as the width, which is nearly one and one-fourth times as wide as the depth. The dorso-median and lateral carinae are well marked. The antennal notch is triangularly concave and the ntero-lateral angle is prominent and acute.

On all the free thoracic segments there are a well marked lateral and a strong dorso-median carinae. The dorso-median carina is elevated posteriorly on the fourth and fifth segments. The first segment is concealed. The second is larger than the others, and about as long as the third and fourth combined.

On all the abdominal segments there is a dorso-median line. The first two segments have a strong elevated dorso-median carina. The fifth segment is longer than the others.

The first joint of peduncle of antennule is about one and one-third times as long as the subequal distal two joints combined. The main flagellum is twojointed and provided with two subequal aesthtascus. The accessory flagellum is single-jointed and very minute.

The basis of third maxilliped is less than twice as long as the remaining distal joints together and serrated on the inner border. The external angle of the basis is developed into a long process, reaching the level about one-half of the merus and furnished with eight plumous hairs. The ischium is nearly as long as the merus, which is somewhat expanded externally. The carpus is about two-thirds as wide as the length, and slightly longer than the merus. The propodus is about one-half as long as the carpus and somewhat expanded laterally. The dactylus is about two-thirds as long as the propodus. 
The basis of first peraeopod is serrated on the inner border and four-fifths as long as the remaining distal joints together. The ischium is nearly one-half as long as the merus. The carpus is one-third as wide as the length, and about one and three-fourths times as long as the merus. The propodus is slightly less

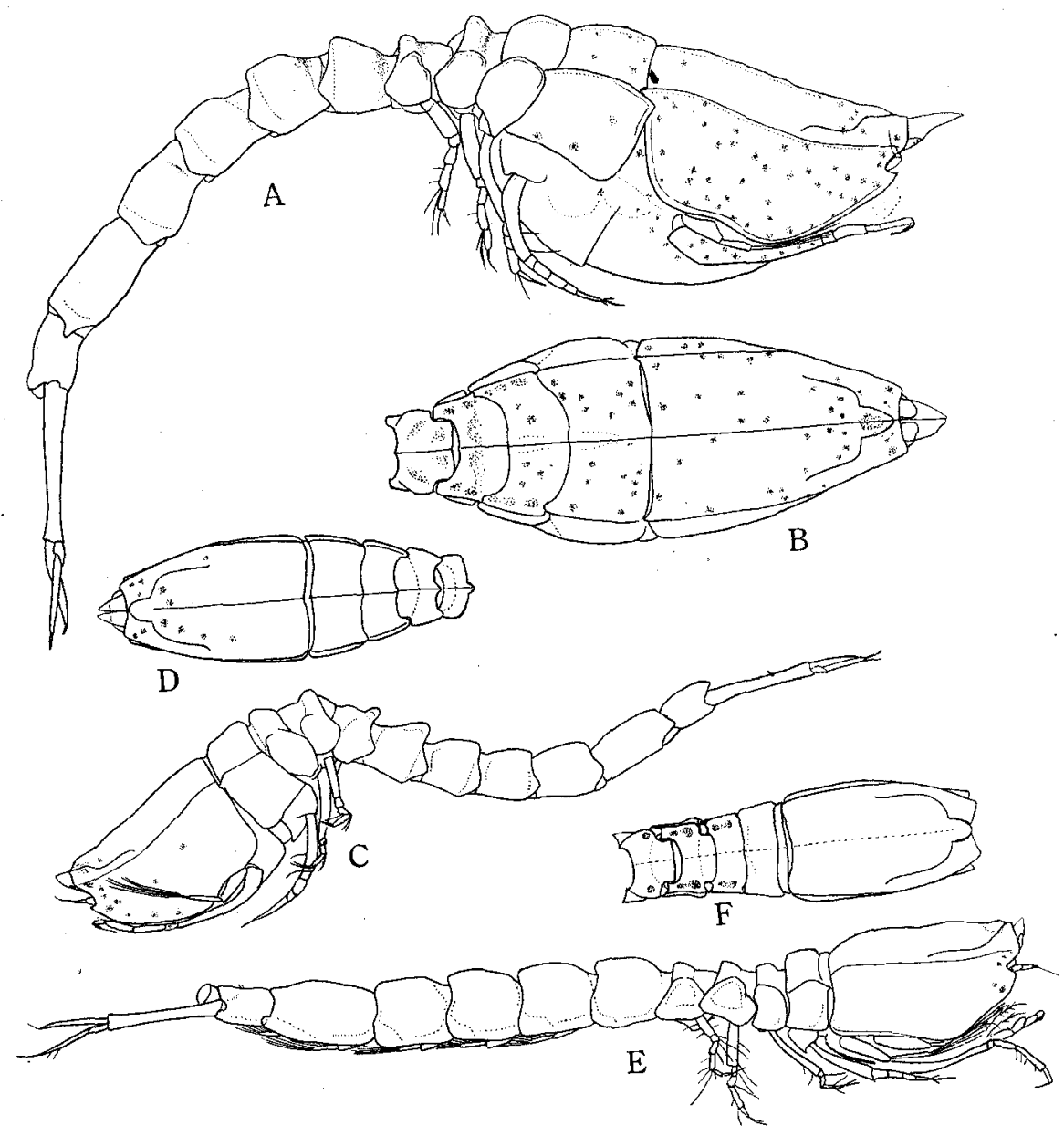

Fig. 3. Bodotria similis CALMAN. Ovigerous female (length, ca. $3.1 \mathrm{~mm}$ ). A : lateral view. B : anterior portion of body, from above. Young female (length, ca. $2.9 \mathrm{~mm}): \mathrm{G}$ : lateral view. $\mathrm{D}$ : anterior portion of body, from above. Male (length, ca. $3.2 \mathrm{~mm}$ ) : $\mathrm{E}$ : lateral view. $\mathrm{F}$ : anterior portion of body, from above.

than one-half as long as the carpus. The dactylus is much shorter than the propodus.

The second peraeopod is six-jointed. The basis is longer than the remaining distal joints together.

The peduncle of uropod is slender, less than twice as long as the last abdominal 


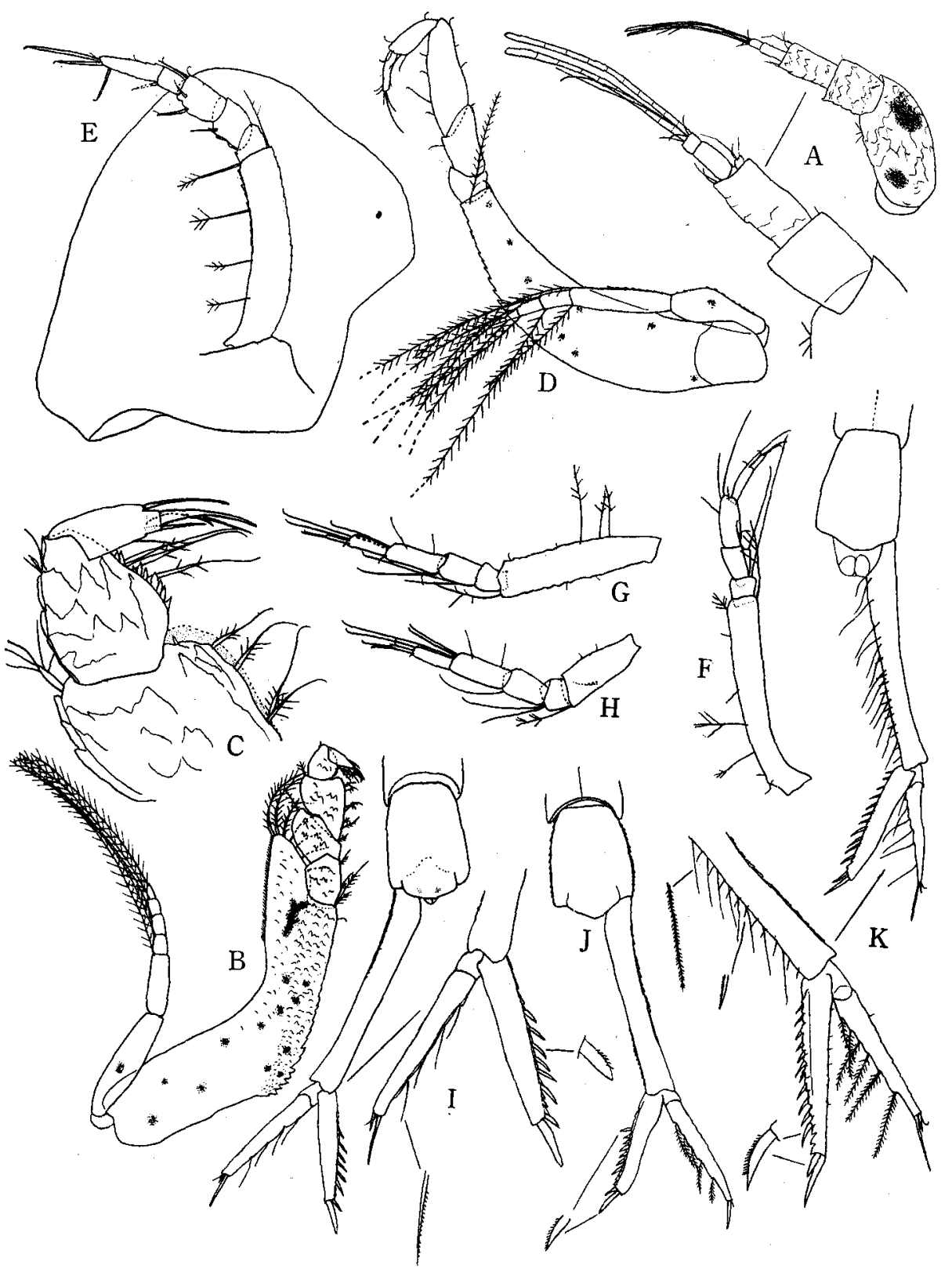

Fig. 4. Bodotria similis CALMAN. Ovigerous female. A : antennule. B : third maxilliped. $\mathrm{C}$ : distal portion of third maxilliped. $\mathrm{D}-\mathrm{H}$ : first to fif th peraeopods. I : uropod with sixth abdominal segment. Young female : $\mathrm{J}$ : uropod with sixth abdominal segment. Male : K : uropod with sixth abdominal segment. 

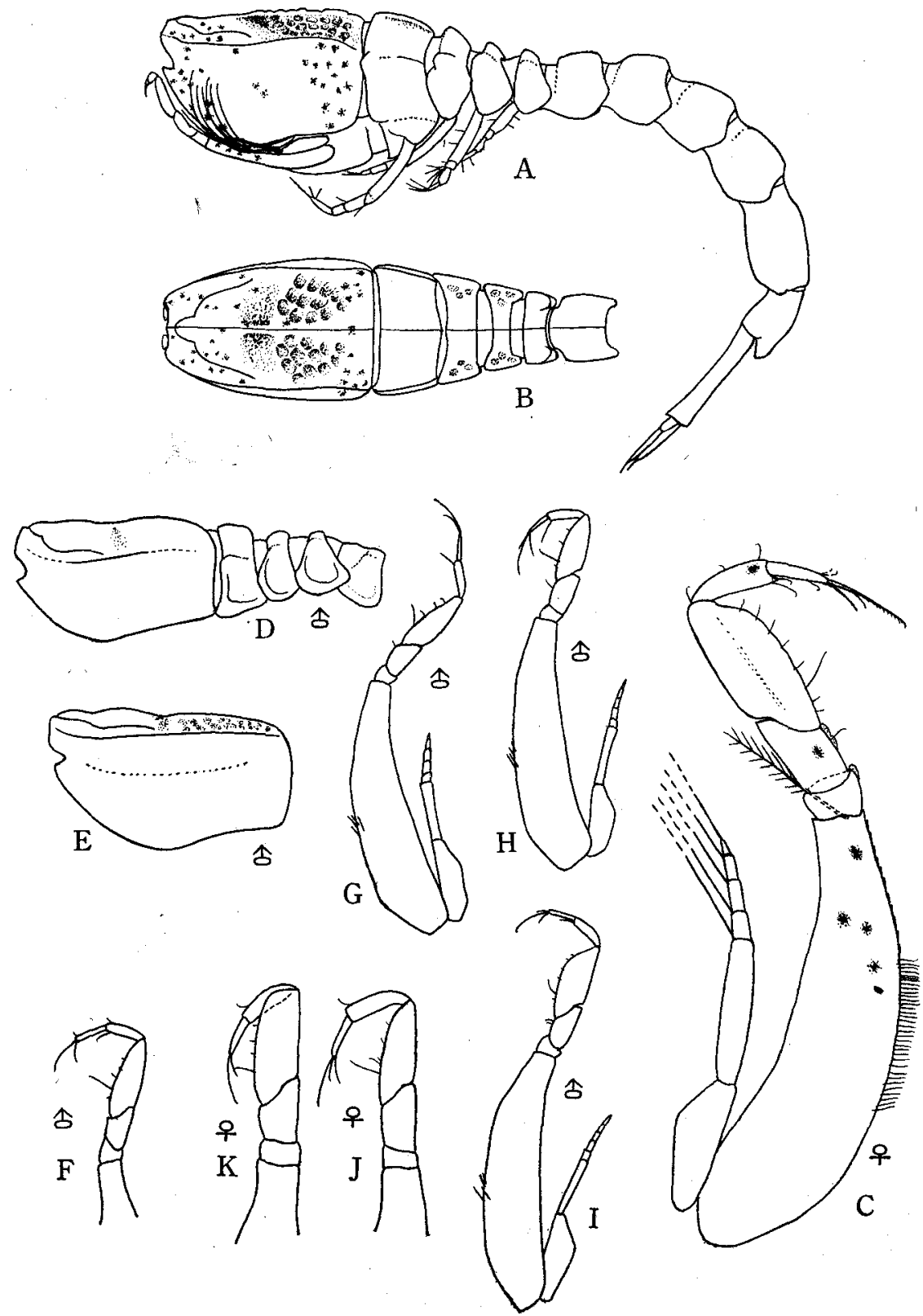

Fig. 5. Bodotria similis CALMAN. Female with developing marsupium (length, ca. $3.8 \mathrm{~mm}$ ) : A : lateral view. B : anterior portion of body, from above. C : first peraeopod. Mature male and female specimens (length, ca. 4-4.8 mm) : D : anterior portion of body, lateral view. $\mathrm{E}:$ carapace, lateral view. $\mathrm{F}-\mathrm{K}:$ distal portion of first peraeopods. 
segment. The endopod is single-jointed, one-half as long as the peduncle, and armed with six spines on the serrated inner border and two spines on the distal end. The exopod is longer than the endopod and furnished with four plumous hairs on the inner border, and two spines and a short hair on the distal end.

Adult male specimen (length, about $3.2 \mathrm{~mm}$ ): The carapace is slightly more than one-fourth of the total length of animal and nearly one and two-thirds times as long as the width, which is about as wide as the depth. The dorso-median and lateral carinae are well marked. The antennal notch and the antero-lateral angle are prominent.

The first free thoracic segment is very short. The second segment is about as long as the fourth or the fifth. The third is less than as long as the second.

Each of the first five abdominal segments is furnished with a dorsal carina, which becomes successively less distinct towards the last.

The basis of third maxilliped is more than twice as long as the remaining distal joints together.

The basis of first peraeopod is slightly more than one and one-half times as long as the remaining distal joints together and furnished with four spines on the middle of the inner edge. The carpus is rather narrow, one-third as wide as the length, and slightly more than one and one-half times as long as the merus.

On the inner border of the peduncle of uropod there are fourteen plumous hairs and twelve spines. The endopod is more than one-half as long as the peduncle, furnished with eleven spines on the serrated inner border and with two terminal spines on the distal end. The exopod is about as long as the endopod and furnished with seven plumous hairs on the inner border and with two spines and a short hair on the distal end.

Female specimen with developing marsupium (length, about $2.9 \mathrm{~mm}$ ): The carapace is less swollen than the ovigerous female described above. The carpus of first peraeopod is one-third as wide as the length. The peduncle of uropod is relatively shorter, about one and two-thirds times as long as the last, abdominal segment.

Female specimen with developing marsupium (length, about $3.8 \mathrm{~mm}$ ): The carapace is about one-fourth as long as the total length of animal and nearly one and one-half times as long as the width, which is slightly more than as wide as the depth. On the dorsal surface there are somewhat conspicuous pitting patterns. The dorso-median carina is well marked on the carapace and as well as on all the free thoracic segments and the abdominal segments. The lateral carina is well marked on the carapace and somewhat faintly marked on the thoracic segments. The abdominal segments are roubust. The carpus of first peraeopod is very dilated, about much more than one-third as wide as the length.

The sizes of the mature specimens of both sexes are ranging aproximatelly from 3 to $4 \mathrm{~mm}$ in length. There appear great variations in the elevation of both dorso-median and lateral carinae on the carapace and as well as on the thoracic 
segments and on the first two abdominal segments, and in the patterning of the reticulate pittings on the carapace. The dilated carpus of first peraeopod is also varies greatly in the shape and the breadth.

In some of the mature male specimens there is a less apparent redge below the lateral carina on the carapace.

Remarks: The specimen resembles very closely B. similis Calman described from Gulf of Siam (CALMAN '07), from which it differs by having the larger body and the carapace of male with less apparent redge below the lateral carina and without such ridge in the female, and having the relatively longer uropod and the dilated carpus of the first peraeopod.

The differences may be due to the geographical and individual variations.

The specimen also resembles very closely B. siamensis CALMAN (CALMAN '07) from Gulf of Siam and B. pumila ZimMER from Formosa (ZIMMER '21), but those differ by the following points of characters: In B. siamensis the lateral carina is inconspicuous on the carapace as well as on the thoracic segments; $B$. pumila has a pair of strong lateral redges on the carapace.

It may be indicated the close affinties between the three species that the features of the specimens, mentioned above, show the intermediate condition of the species.

It seems to me that $B$. pumila is identical with $B$. similis as F AGE (45) pointed out, and that $B$. siamensis may be perhaps synonymous with $B$. similis.

CAIMAN (12) reported a single female specimen, as an undescribed species of this genus, from Japan (off Omai Zaki, surface tow-net), which has the very dilated carpus of the first peraeopod and a strong marked lateral redge on the carapace as well as on the thoracic segments; but it was not fully described as the specimen was imperfect conditions. The CaLMaN's female specimen may also be identical with the present species.

The species is very closely related to $B$. maculosa HALE from Autralia, from which it differs by having the carapace without strongly marked pittings and much longer uropod.

Occurrence: many $\hat{o}$ and $\circ$ (mature and immature).

Distribution: Trivandrum and Andamans, Gulf of Siam, Vietnam, Formosa ; Japan (Omai Zaki).

\section{Cyclaspis strumosa HALE}

(Fig. 6)

Cyclaspis strumosa HALE (1948) p. 13, figs. 7-9.

C. strumosa, KuRIAN (1954) p. 280.

Immature male specimen (length, about $3.3 \mathrm{~mm}$ ): The specimen is very identical with HALE's description of subadult male specimen (length, $3.7 \mathrm{~mm}$ ) from Western Australia. 


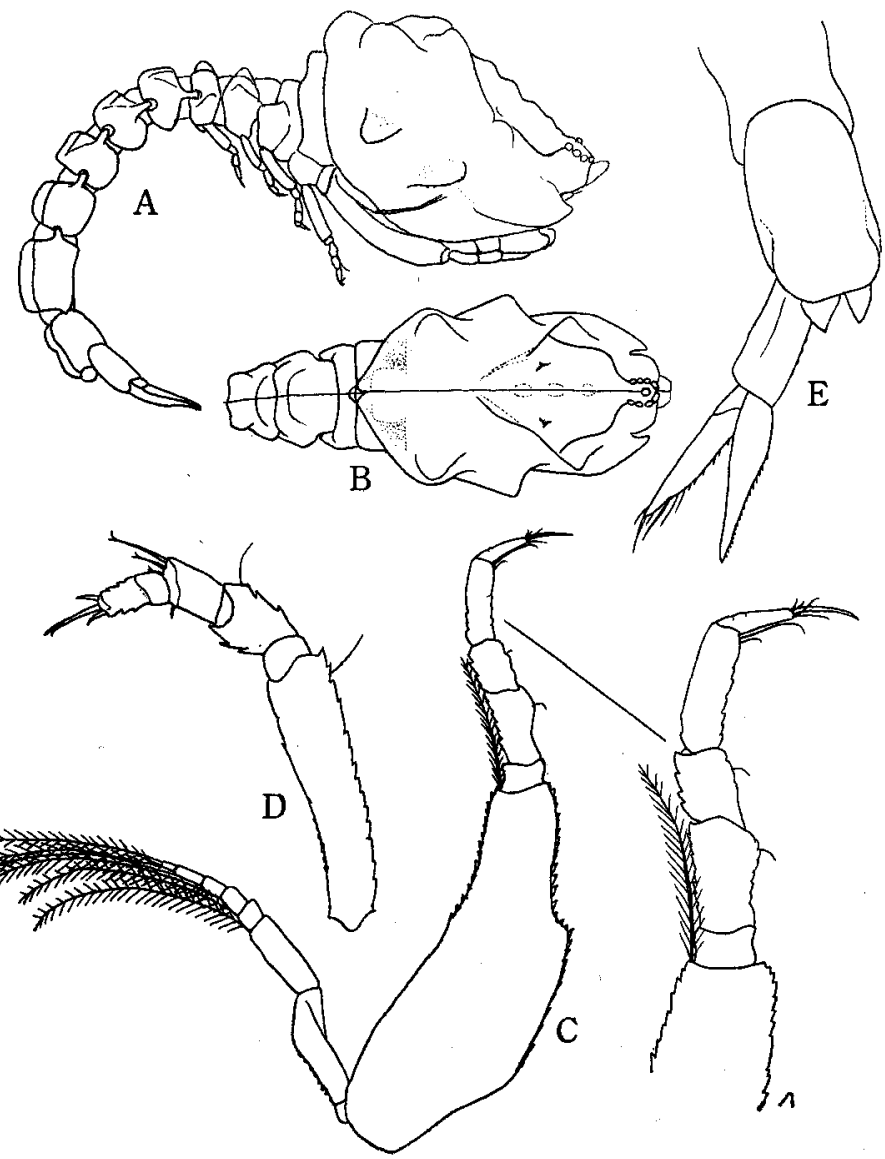

Fig. 6. Cyclaspis strumosa HALE. Immature male (length, ca. $3.3 \mathrm{~mm}$ ). A : lateral view. B : anterior portion of body, from above. C-D : first and second peraeopods. E : uropod with sixth abdominal segment. 
Occurrence: $3 \sigma^{\top}$ (immature), 2 (manca stage).

Distribution: Western Australia, Queensland, Andaman Sea.

\section{Cyclaspis bidens sp. nov.}

(Figs. 7, 8)

Type subadult male specimen (length, about $4.2 \mathrm{~mm}$ ): The carapace is much more than one-fourth of the total length of animal and a little less than twice as long as the width, which is nearly one and one-fifth times as wide as the depth. The dorso-median carina is well marked. The surface is sparsely granulose. The

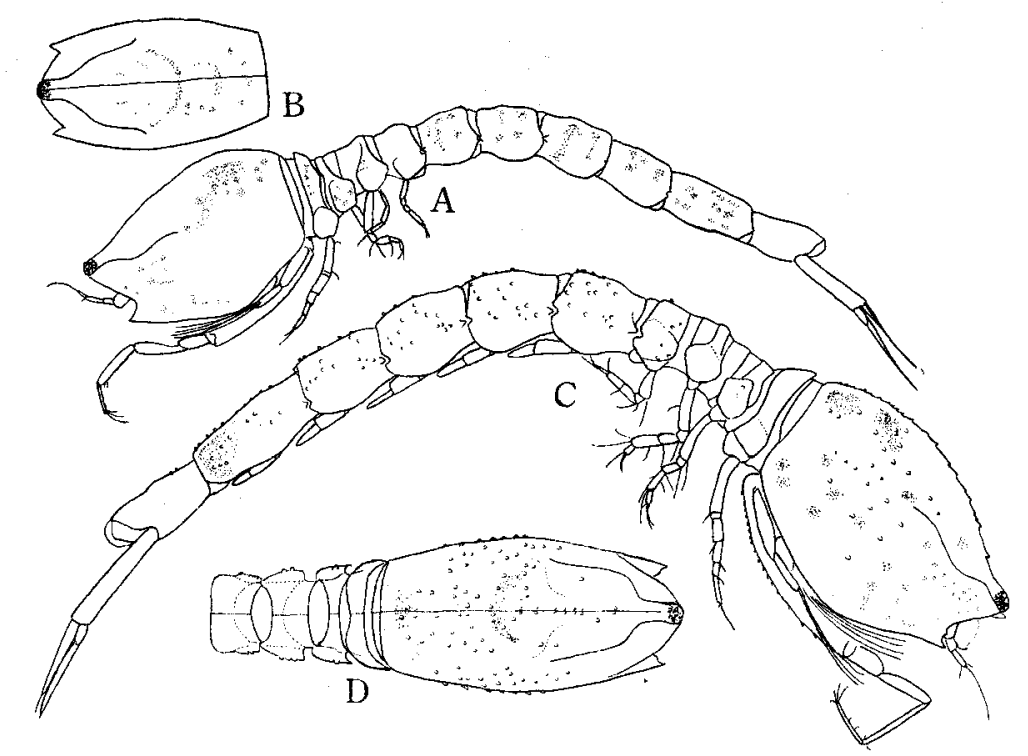

Fig. 7. Cyclapis bidens sp. nov., type subadult male (length, ca. $4.2 \mathrm{~mm}$ ): A : lateral view. B : carapace from above. Paratype young female (length, ca. $3.4 \mathrm{~mm}$ ) : C : leteral view. D : anterior portion of body, from above.

antennal notch is angularly concave. The antero-lateral angle is acute and provided with a small tooth on the inner edge. The pseudorostral lobes are reaching to the level of apex of ocular lobe, but barely meeting in front of it. The ocular lobe is digitiform and twice as long as the width and beset with small eyes.

The combined length of all the free thoracic segments is slightly less than two-thirds as long as the carapace. Each of the segments is provided with a dorso-median and a lateral carinae. The first is only partly concealed, the exposed part is very short.

The first joint of peduncle of antennule is twice as long as the third, which 
is slightly longer than the second. The main flagellum is two-jointed and provided with two subequal aesthetascus. The accessory flagellum is minute.

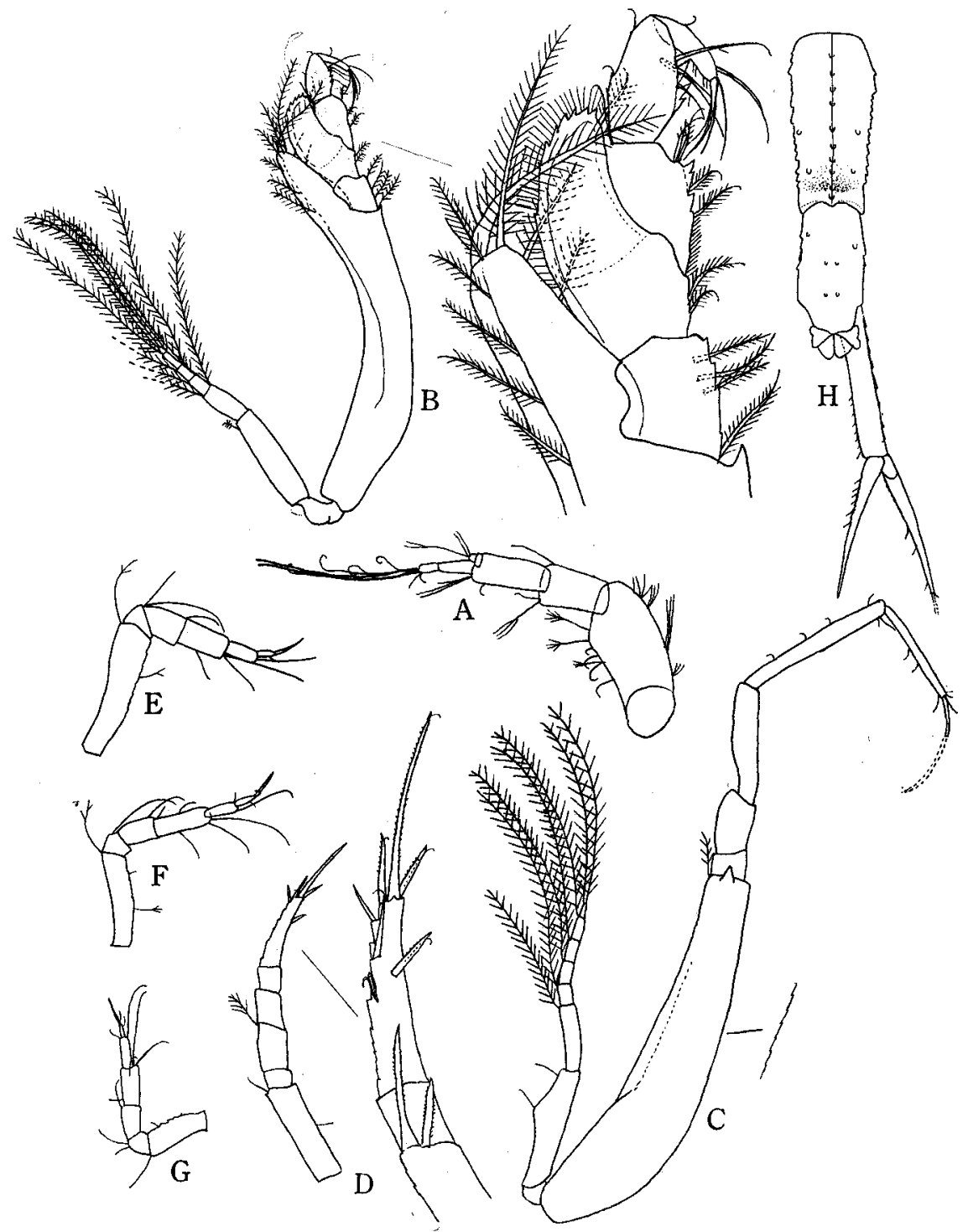

Fig. 8. Cyclaspis bidens sp. nov., type subadult male. A : antennule. B : third maxilliped. $\mathrm{C}-\mathrm{G}$ : first to fifth peraoepods. $\mathrm{H}$ : uropod with fifth and sixth abdominal segments.

The basis of third maxilliped is one and five-sixths times as long as the remaining distal joints together. The external angle is developed into a long process reaching to the middle of the merus and furnished with plumous hairs. 
The merus is twice as long as the ischium and the external angle is also developed into a such process reaching to the level about one-fourth of the propodus. There are fine hairs on the outer edge. The carpus is about one-half as long as the merus and nearly as long as the propodus. The dactylus is two-thirds as long as the propodus.

The basis of first peraeopod is seven-eighths as long as the remaining distal joints together, a little serrated on the inner border and furnished with a tooth on the distal end. The merus is slightly more than one-half as long as the carpus. The carpus is three-fourths as long as the propodus, which is one and one-half times as long as the dactylus.

The second peraeopod is about as long as the third and longer than the fourth or the fifth. The basis is a little more than one-half as long as the remaining distal joints together. The merus is longer than the carpus, which is about one and one-half times as long as the propodus. The carpus has two unequal spines on the distal end. The dactylus is nearly three times as long as the propodus and furnished with three lateral small spines and three terminal spines. The longest terminal spine is as long as the dactylus.

The dorso-median carina is well marked on each of the first five abdominal segments. The first four segments are about subequal in length. The fifth is nearly one and one-half times as long as the fourth. The sixth is a little more than the fourth.

The peduncle of uropod is much longer than the last abdominal segment and furnished with fine hairs on the inner border and serrations on the outer. Both rami are narrow and apically acute. The endopod is slightly shorter than the peduncle. The exopod is about as long as the endopod and furnished with setae on the inner and outer borders and a spine on the distal end.

Young female specimen (length, about $3.4 \mathrm{~mm}$ ): The carapace is much more than one-fourth of the total length of animal and slightly more than one and twothirds times as long as the width, which is much less than the depth. The surface is beset with no sparse granules. The antennal notch is angularly concave and furnished with no small tooth on the inner edge.

The combined length of free thoracic segments is slightly more than threefifths as long as the carapace.

The first joint of peduncle of antennule is more than twice as long as the third, which is as long as the second.

The basis of third maxilliped is much less than one and five-sixths times as long as the remaining distal joints together. The merus is more than twice as long as the ischium. The carpus is more than one-half as long as the merus and as long as the propodus. The dactylus is a little less than one-half as long as the propodus.

The propodus of first peraeoped is more than as long as the carpus and a little more than one-half as long as the dactylus. 
The second peraeopod is longer than the third or the fourth and much longer than the fifth. The basis is slightly more than two-thirds as long as the remaining distal joints together. The merus is nearly twice as long as the propodus.

The first five abdominal segments are successively increase in length and provided with a faint dorso-median carina. The fifth is nearly one and one-third times as long as the fourth. The sixth is about as long as the fourth.

The peduncle of uropod is slightly longer than the last abdominal segment and about as long as the subequal rami.

Remarks: The subadult male specimen of the new species is very closely related to C. bengalensis KURIAN, which was described by KURIAN ('54) based on an adult male specimen from Andamans, but it may be mainly distinguished as follows: The depth of carapace of the new species is much more than one-half of its length and much more than the width; the basis of third maxilliped has the external process reaching the middle of the merus; the first peraeopod has the merus without a tooth-like prolongation on the outer side.

Occurrence: 1 o (type specimen), 1 ㅇ.

\section{Iphinoe sagamiensis GAMô}

(Fig. 9)

Iphinoe sagamiensis GAMÔ (1958) pp. 385, 388, fig. 2 ; (1960c) p. 118, pl. 59, fig. 3.

Paratype adult male specimen (length, about $6.2 \mathrm{~mm}$ ): The carapace is onefourth of the total length of animal and nearly three times as long as the width, which is a little less than the depth. The dorso-median carina is well marked. There are a forwardly directed tooth on the anterior portion of frontal lobe and about four spaced minute spinules on the anterior half of the dorso-median carina. The antero-lateral angle is prominent and rounded at its apex; the outer margin of it is furnished with six serrations. The lower margin is convex in the middle portion. The pseudorostral lobes are about one-ninth as long as the carapace. The ocular lobe is prominent and provided with a pair of rudimentary spinules.

The second sternite is smooth, very shallowly concave in the middle portion and not armed with any armatures. The third sternite is furnished with a broad and large median tubercle in the middle portion.

The first joint of peduncle of antennule is much longer than the third. The second is much shorter than the third.

The basis of first peraeopod is much shorter than the remaining distal joints together and serrated on both lateral borders. There are a plumous hairs and several teeth on each distal edge of basis and ischium.

The abdomen is much more than as long as the carapace and as long as all the free thoracic segments together.

The peduncle of uropod is somewhat slender and longer than the last 
abdominal segment. There are about thirteen spines on the anterior half of the inner border and about thirty plumous spines on the posterior half. The endopod is two-jointed and much shorter than the peduncle. The first joint is two-thirds as long as the second and armed with about ten spines on the inner border. The

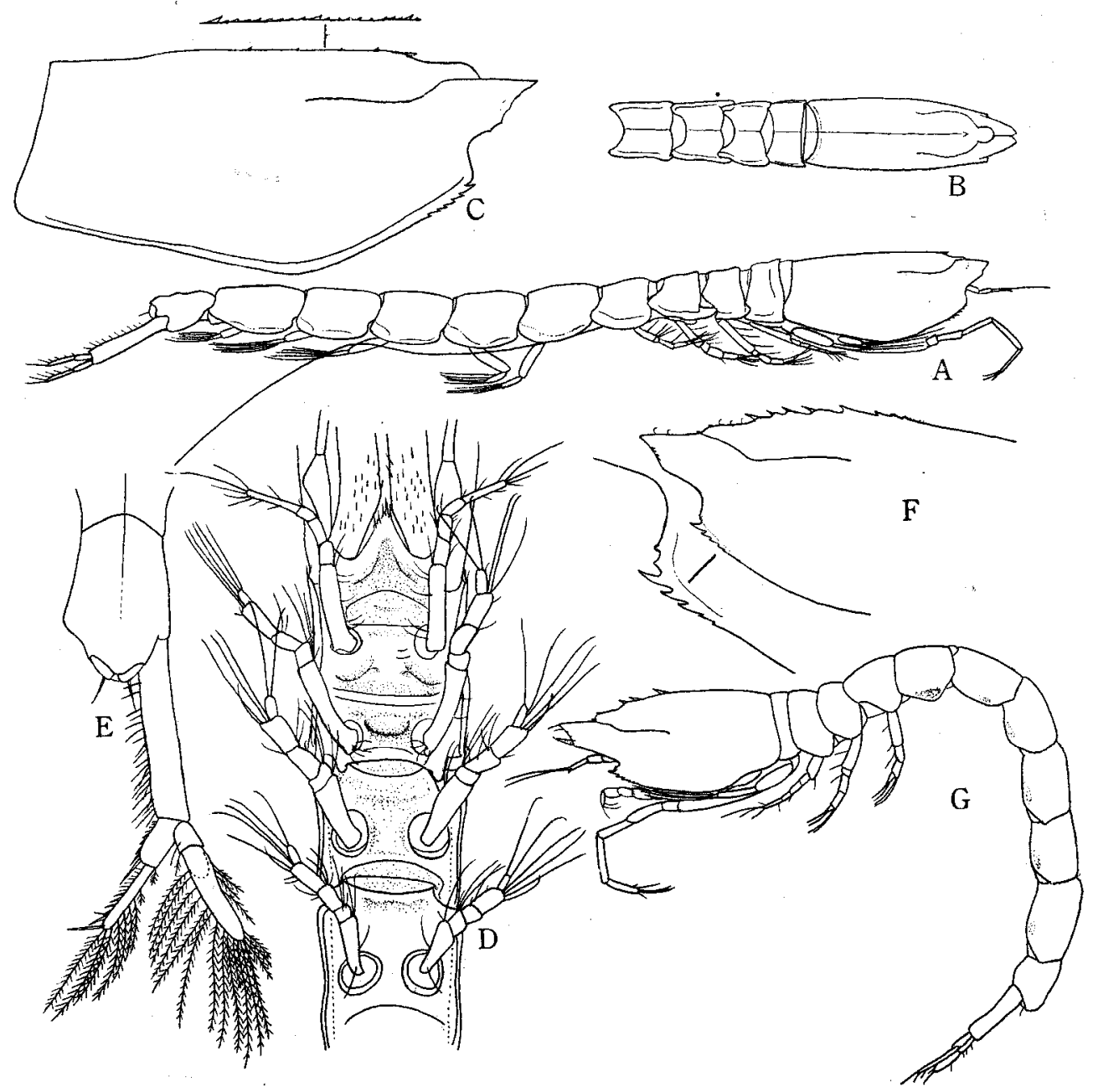

Fig. 9. Iphinoe sagamiensis GAMô. Adult male (length, ca. $6.7 \mathrm{~mm}$ ). A : lateral view. B : anterior portion of body, from above. $C$ : carapace, lateral view. $D$ : thoracic sternites, from below. E : uropod with fifth abdominal segment. Young male (length, ca. $5.5 \mathrm{~mm}$ ): $\mathrm{F}$ : anterior portion of carepace, lateral view. Manca stage (length, ca. $2.6 \mathrm{~mm}$ ) : G : lateral view.

second joint is armed with sixteen spines on the inner border, six plumous hairs on the outer and two such hairs on the distal end. The exopod is nearly as long as the endopod and furnished with ten plumous hairs on the inner border, four on the proximal portion of the outer and six on the distal end. 
Immature male specimen (length, about $5.5 \mathrm{~mm}$ ): The carapace is provided with about eight teeth on the anterior half of the dorso-median carina. The rounded antero-lateral angle is furnished with five serrations on the outer margin and two rudimentary teeth on the inner.

Manca stage (length, about $2.6 \mathrm{~mm}$ ): The carapace has a longitudinal row of three forwardly directed teeth on the anterior portion. The fifth free thoracic segment has no peraeopod.

Occurrence: $14 \sigma^{7}, 18 \% ; 3$ (manca stage).

Distribution: Sagami Bay.

\section{Family Nannastacidae}

\section{Nannastacus japonicus sp. nov.}

(Figs. 10, 11)

Nannastacus sp., GAMô (1960c) p. 118, pl. 59, fig. 6 .

Type adult male specimen (length, about $2.3 \mathrm{~mm}$ ): The carapace is almost smooth, but beset with armatures like scales. The length is two-fifths as long as the total length of animal and twice as long as the width, which is more than as wide as the depth. The dorsal surface is flattened posteriorly, sloping downwards towards the eyes anteriorly. The branchial regions are slightly swollen. The dorso-median carina is faintly marked. There is no distinct antennal notch. The antero-lateral margin of carapace is very short and meets the lower margin nearly at right angles. The eyes are set near together, very large and redish pigmented in alive, each with three large corneal lenses. The pseudorostral lobes are prominent, meeting for a distance slightly more than one-fourth as long as the length of carapace and serrated at anterior ends.

On all the free thoracic segments there is a faint dorso-median carina. The first segment is nearly as wide as the carapace and partly concealed. The pleural parts of second to fourth are somewhat broadly expanded.

The first joint of peduncle of antennule is about one and one-half times as long as the third, which is much longer than the second. The accessory flagellum is relatively large, single-jointed and nearly one-half as long as the two-jointed main flagellum.

The basis of third maxilliped with an exopod is much longer than the remaining distal joints together. The propodus is longer than the carpus.

The basis of first peraeopod is more than two-thirds as long as the remaining distal joints together. The carpus is as long as the propodus, which is about three times as long as the dactylus.

The second peraeopod is much longer than four-fifths of the first. The basis is much longer than the remaining distal joints together. The ischium is about as long as the merus, which is longer than one-half as long as the carpus. The 
dactylus is about as long as the carpus and about as long as the propodus. The longest distal spine of dactylus is about one and one-half times as long as the dactylus.

The carpus of fifth peraeopod is less than three times as long as the merus and less than twice as long as the propodus, which is longer than the dactylus.

The peduncle of uropod is slightly more than three times as long as the last abdominal segment and a little less than twice as long as the endopod, which is about one and one-third times as long as the exopod. The peduncle of uropod is furnished with short hairs on both edges. The endopod has spinules on both proximal edges, six spines interspersed with spinules on the inner edge, a lateral spine on the outer distal and one short and a long spines on the distal end. The endopod has a long terminal spine and two spines on the inner edge, and a spine on the serrated outer edge.

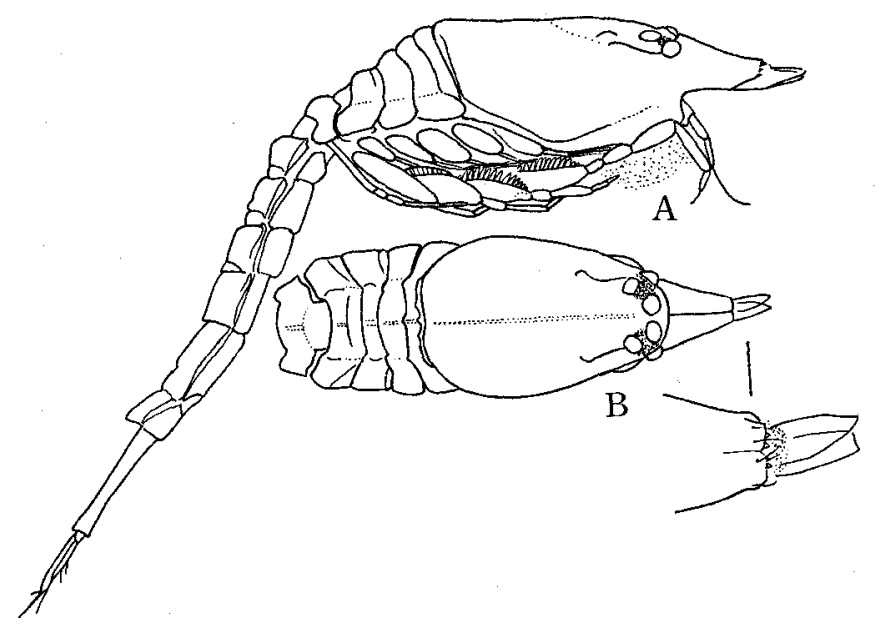

Fig. 10. Nannastacus japonicus sp. nov., type male (length, ca. $2.3 \mathrm{~mm}$ ). A : lateral view. B : anterior portion of body, from above.

Remarks: The new species is very closely related to $N$. longirostris SARS (Sars 1879, Stebbing '13, Fage '51), N. brachydactylus Calman (CAlman '05a) and N. nasiutus var. camelus ZIMMER (ZIMMER '14, HALE '45).

These may be distinguished from the new species as follows: The pseudorostrum of $N$. longirostris is much longer than that of the new species; in $N$. brachydactylus the peduncle of uropod is about two and one-half times as long as the last abdominal segment and a little more than one and one-half times as long as the endopod; the carpus of fifth peraeopod of $N$. nasiutus var. camelus is more than three times as long as the merus, which is almost as long as the propodus.

Occurrence: many $\hat{o}(1 \hat{\delta}$, type specimen).

Distribution: Sagami Bay. 


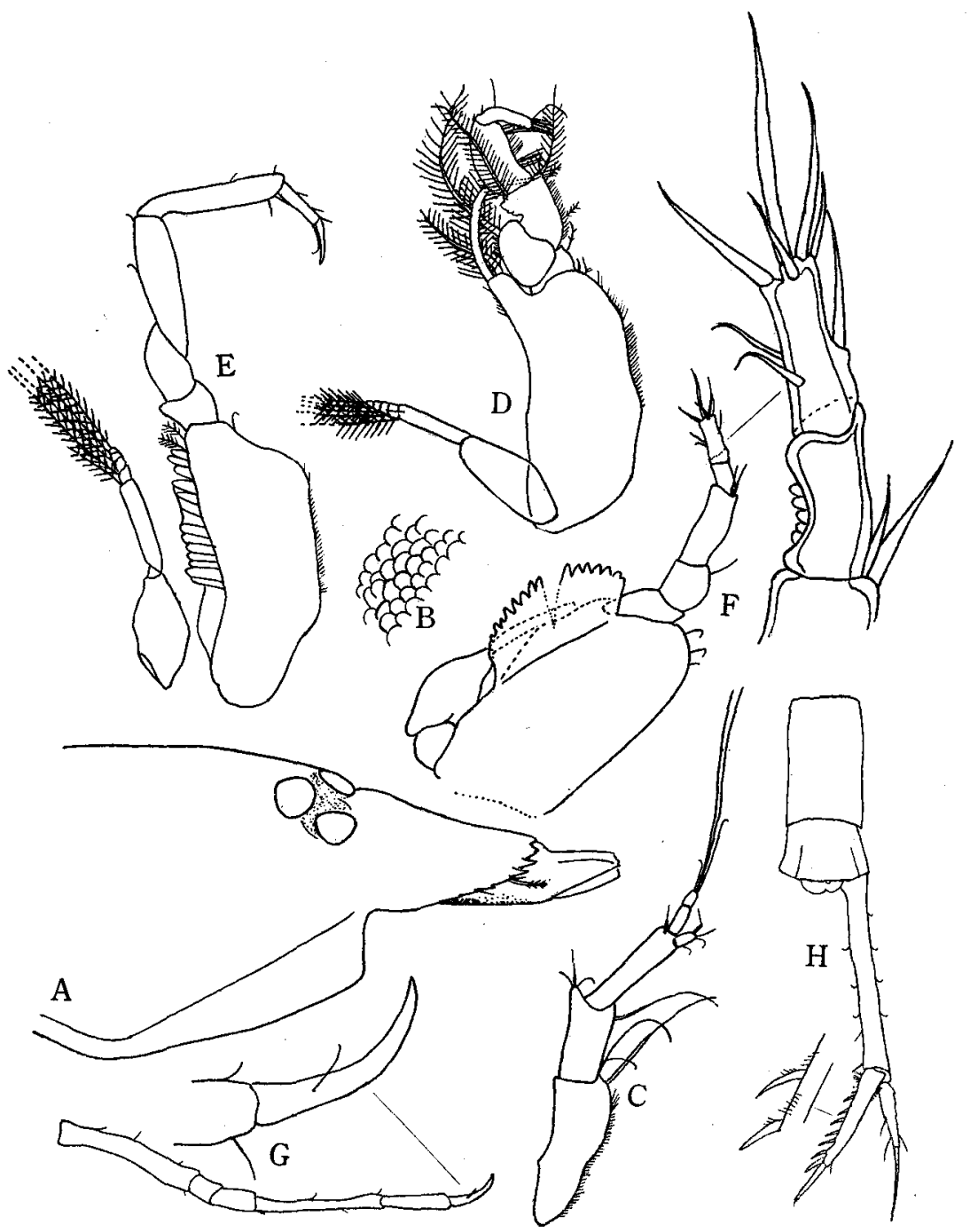

Fig. 11. Nannastacus japonicus sp. nov., type male. A : anterior portion of carapace, lateral view. B : sculptures of carapace. $\mathrm{C}:$ antennule. $\mathrm{D}$ : third maxilliped. E-F : first and second peraeopods. G : fifth peraeopod. $\mathrm{H}$ : uropod with fifth and sixth abdominal segments. 


\section{Nannastacus pruinosus sp. nov.}

(Figs. 12, 13)

Type adult male specimen (length, about $2.0 \mathrm{~mm}$ ): The integument is closely beset with minute glassy spiniform granules. The carapace is much more than one-third as long as the total length of animal and a little less than twice as long as the width, which is three-fourths as wide as the depth. The antero-lateral and the branchial regions are a little swollen and the posterior median portion is tumid. The antero-lateral margin is deeply and angularly concave; the anterolateral angle is furnished with a short spine. The antero-lateral or lower border of carapace is beset with spinules. The pseudorostal lobes are triangular, widely separated both above and below.

The free thoracic segments are almost covered with minute spiniform granules.

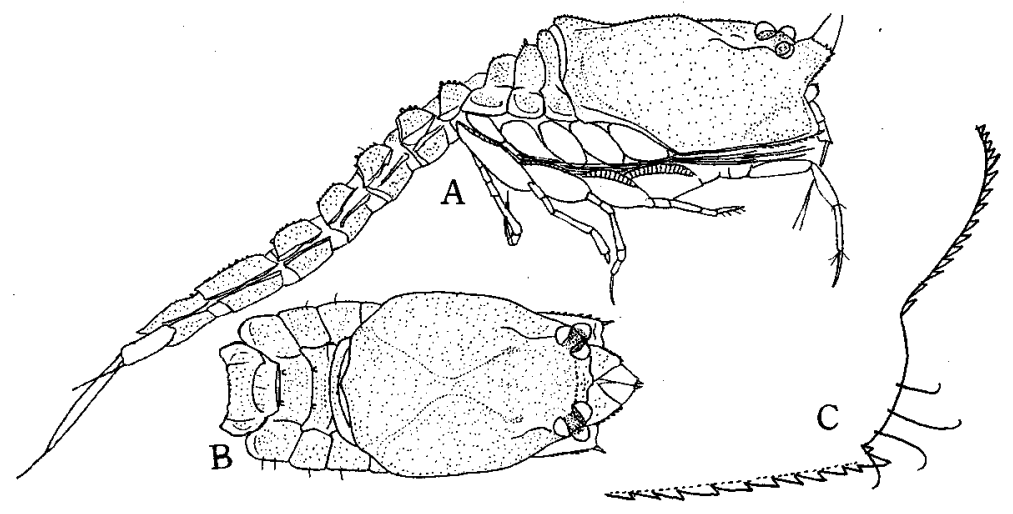

Fig. 12. Nannastacus pruinosus sp. nov., type male (length, ca. $2.0 \mathrm{~mm}$ ). A : lateral view. $B$ : anterior portion of body, from above. $C$ : antero-lateral portion of carapace.

There are a pair of small spinules on each dorso-median portion of the first, third and fourth segments. The first segment is very short and the pleural parts are concealed. The pleural parts of the second to fourth are somewhat expanded laterally. The fifth is much smaller than the others and about one-half as wide as the carapace.

The first joint of peduncle of antennule is a little more than three-fourths as long as the subequal distal two joints combined.

The basis of third maxilliped with an exopod is about as long as the remaining distal joints together. The carpus is a little less than the propodus

The basis of first peraeopod is more than two-thirds as long as the remaining distal joints together. The merus is more than one-half as long as the carpus, which is much longer than the propodus. The dactylus is much more than onehalf as long as the propodus. 
The second peraeopod is nearly two-thirds as long as the first. The basis is about one and one-third times as long as the remaining distal joints together. The carpus is about one and one-half times as long as the merus and longer than the subequal distal two joints combined. The longest distal spine of dactylus is

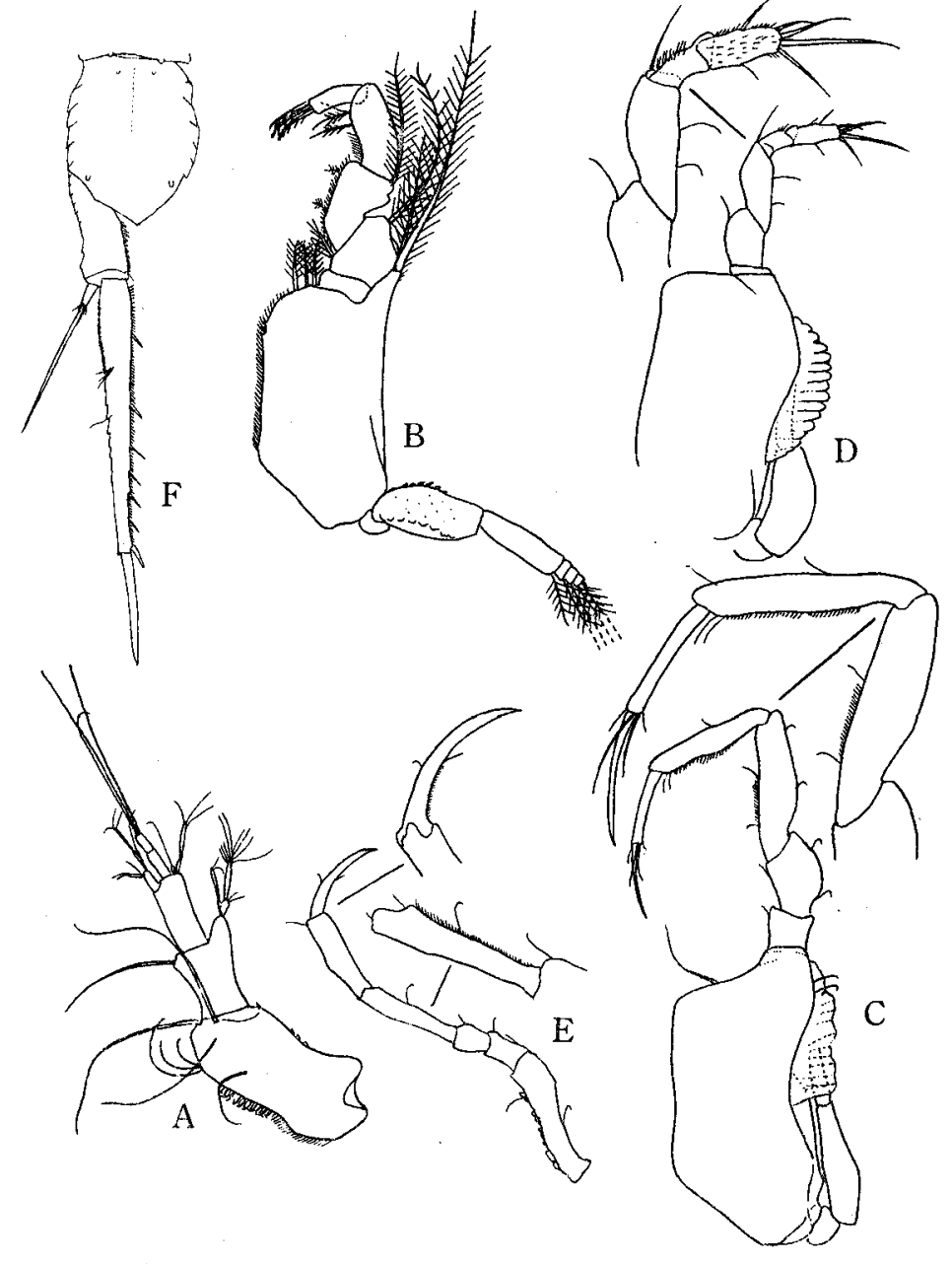

Fig. 13. Nannastacus pruinosus sp. nov., type male. A : antennule. B : third maxilliped. C-D : first and second peraeopods. $\mathrm{E}$ : fifth peraeopod. $\mathrm{F}$ : uropod with sixth abdominal segment.

as long as the propodus and dactylus combined.

The carpus of fifth peraeopod is a little longer than the propodus.

The last abdominal segment is one and one-third times as long as the width and serrated on both edges. 
The peduncle of uropod is two-thirds as long as the last abdominal segment, serrated on both edges and furnished with spinules on the inner. The endopod is about two and one-half times as long as the peduncle. There are five serrations and about four hairs on the outer edge, seven spines interspersed with spinules on the inner and a long stout terminal spine, which is two-fifths as lang as the endopod. The exopod is very short, slightly less than one-fourth as long as the peduncle and has a long terminal spine, which is much more exceeding the middle of the endopod.

Remarkes: The new species is very closely related to $N$. suhmii Sars (Sars 1887), N. georgi Stebbing (Stebbing 1900), N. zimmeri Calman, $N$. minor Calman, $N$. gibbosus Calman (CAlman '11), $N$. sauteri Zimmer and $N$. mystacineus Zimmer (ZIMMER '21).

Those may be mainly distinguished from the new species are as follows: The antero-lateral angle of the male of $N$. suhmii, N. sauteri and N. mystacineus is provided with none of spines or teeth; on the surface of carapace of $N$. georgi there are reticulations with hexagonal or scale-like markings; the peduncle of uropod of $N$. gibbosus is larger than the last abdominal segment; in $N$. zimmeri the endopod of uropod is much longer than three times as long as the peduncle and the terminal spine of exopod reaches just middle of the length of the endopod (exclusive of the terminal spine of endopod); $N$. minor is considerably smaller size (length, $1.3 \mathrm{~mm}$ : CALMAN '11) and provided with a large antero-lateral eye on each side of the eye lobe.

It is also very closely related to $N$. inflatus HALE and $N$. subinflatus HALE (HALE '45), from which it differs mainly in the shape of the last abdominal segment.

Occurrence: $48 \hat{\jmath}$ ( $1 \hat{o}$, type specimen).

\section{Nannastacus nudus sp. nov.}

(Figs. 14, 15)

Type male specimen (length, about $1.7 \mathrm{~mm}$ ): The carapace is somewhat depressed, furnished with scale-like tubercles, about three-eighths as long as the total length of animal and more than one and one-half times as long as the width, which is a little more than four-fifths as wide as the depth. The dorsal surface is uneven. The postero-dorsal margin is produced backwards and almost concealed the first free thoracic segment. The eyes is widely separated, each is furnished with the usual three corneal lenses. The antero-lateral angle is rounded, and furnished with a spinule on the outer edge. The antero-lateral margin is shallowly concave in the middle; the postero-lateral or lower margin is entirely smooth. The pseudorostral lobes are about one-twelfths as long as the carapace and 


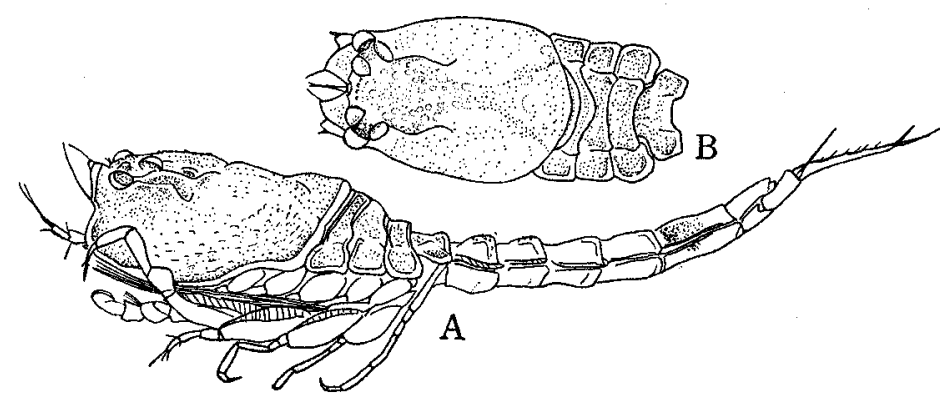

Fig. 14. Nanniastacus nudus sp. nov., type male (length, ca. $1.7 \mathrm{~mm}$ ). A : lateral view. B : anterior portion of body, from above.

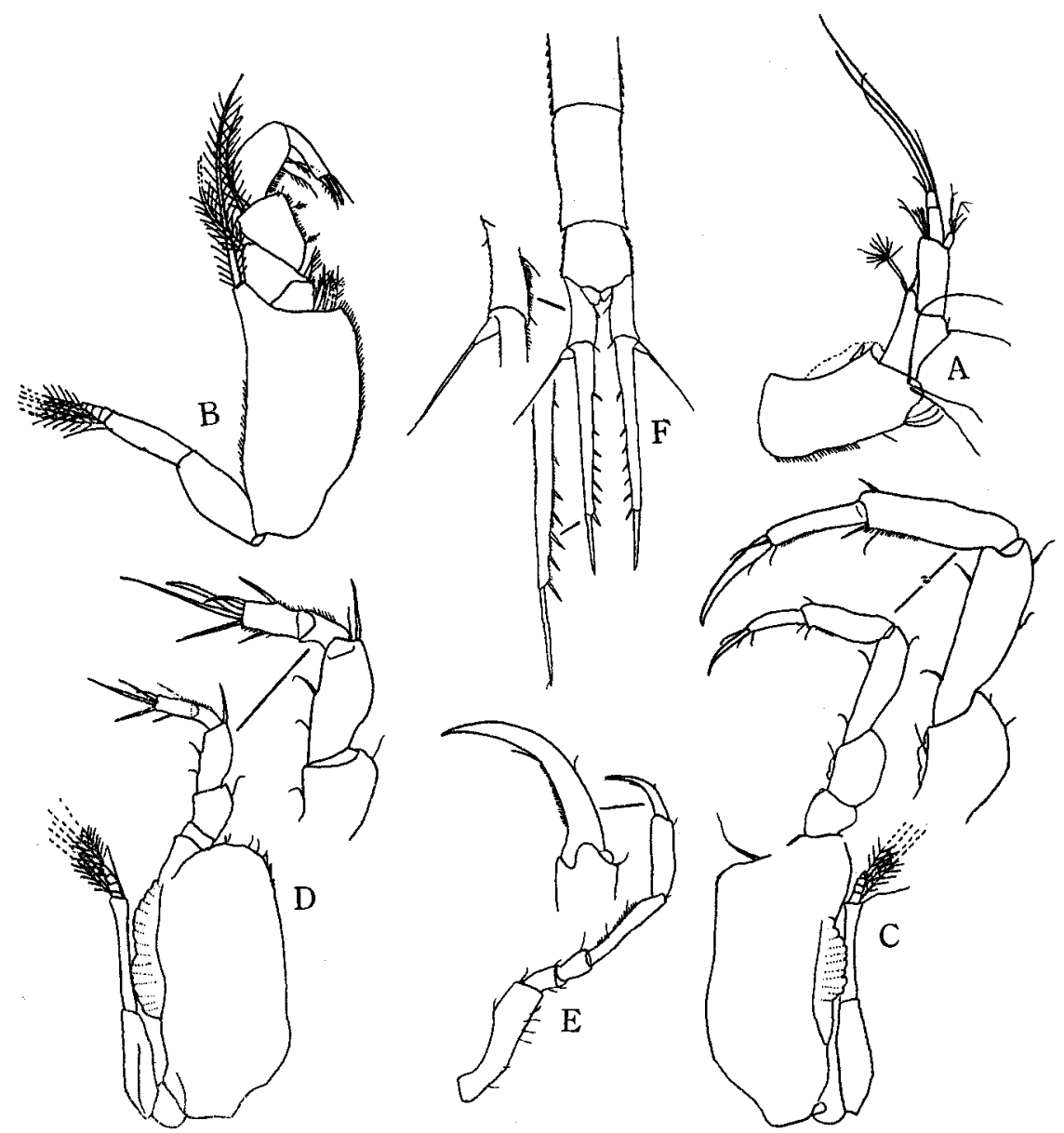

Fig. 15. Nannastacus nudus sp. nov., type male. A : antennule. B : third maxilliped. C-D : first and second peraeopods. E : fifth peraeopod. F : uropod with fifth and sixth abdominal segments. 
subtriangular, and each is widely separated both above and below. From the side the pseudorostral lobe is widely truncated.

The free thoracic segments are not provided with any armatures on the surfaces. The first segment is very short and concealed on both sides. Each of the second to fourth is nearly as wide as the carapace and the pleural parts are somewhat expanded laterally. The fifth is much smaller than the others.

The first joint of peduncle of antennule is a little less than the distal two joints together. The second is shorter than the third.

The basis of third maxilliped with an exopod is as long as the remaining distal joints together. The carpus is about as long as the propodus.

The basis of first peraeopod is four-fifths as long as the remaining distal joints together. The merus is nearly two-thirds as long as the carpus, which is a little less than one and one-half times as long as the propodus. The dactylus is about two-thirds as long as the propodus.

The second peraeopod is shorter than three-fourths as long as the first. The basis is less than one and one-half times as long as the remaining distal joints together. The merus is about two-thirds as long as the carpus, which is as long as the subequal distal two joints combined.

The last abdominal segment is as long as its width and furnished with serrations on both edges.

The peduncle of uropod is a little less than as long as the last abdominal segment and beset with serrations on the outer edge and spinules on the inner. The endopod is about two and one-half times as long as the peduncle. There are serrations on the outer edge, seven lateral spines interspersed with spinules on the inner and a long spine on the distal end, which is about two-fifths as long as the endopod. The exopod is short, about one-fourth as long as the peduncle and furnished with a long terminal spine, which is about five times as long as the exopod.

Remarks: The new species is very closely allied to $N$. pruinosus, from wrich it differs by having the carapace without minute glassy spiniform granules.

Occurrence: 1 s (type specimen).

\section{Nannastacus goniatus sp. nov.}

(Figs. 16, 17)

Type adult female specimen (length, about $1.7 \mathrm{~mm}$ ) : The carapace is expanded postero-laterally, the widest across the posterior portion and raised postero-dorsally. The length is about two-thirds as long as the total length of animal and less than one and one-third times as long as the width, which is more than one and one-third times as wide as the depth. There are sparse hairs on the dorsal surface and spiniform granules on the posterior border. The antero-lateral border is deeply concave at right angles. The antero-lateral angle is produced as an acute tooth. 
The pseudorostral lobes are directed upward and gaping above and below.

The pleural parts and a narrow dorsal stripe of the first free thoracic segment is exposed. The second is also elevated and short. The first three segments are wider than the carapace. The fourth and fifth are less than as wide as the carapace. The pleural parts of all the segments are expanded laterally and fringed with sparse hairs and spiniform granules.

The abdomen is slightly shorter than one-half of the total length of animal. On each dorsal surface of the segments there are sparse hairs and the first two segments have spiniform granules. The first four segments are about subequal in length. The fifth and sixth are larger and subequal in length. The sixth abdominal segment is nearly as long as the width, and rounded posteriorly.

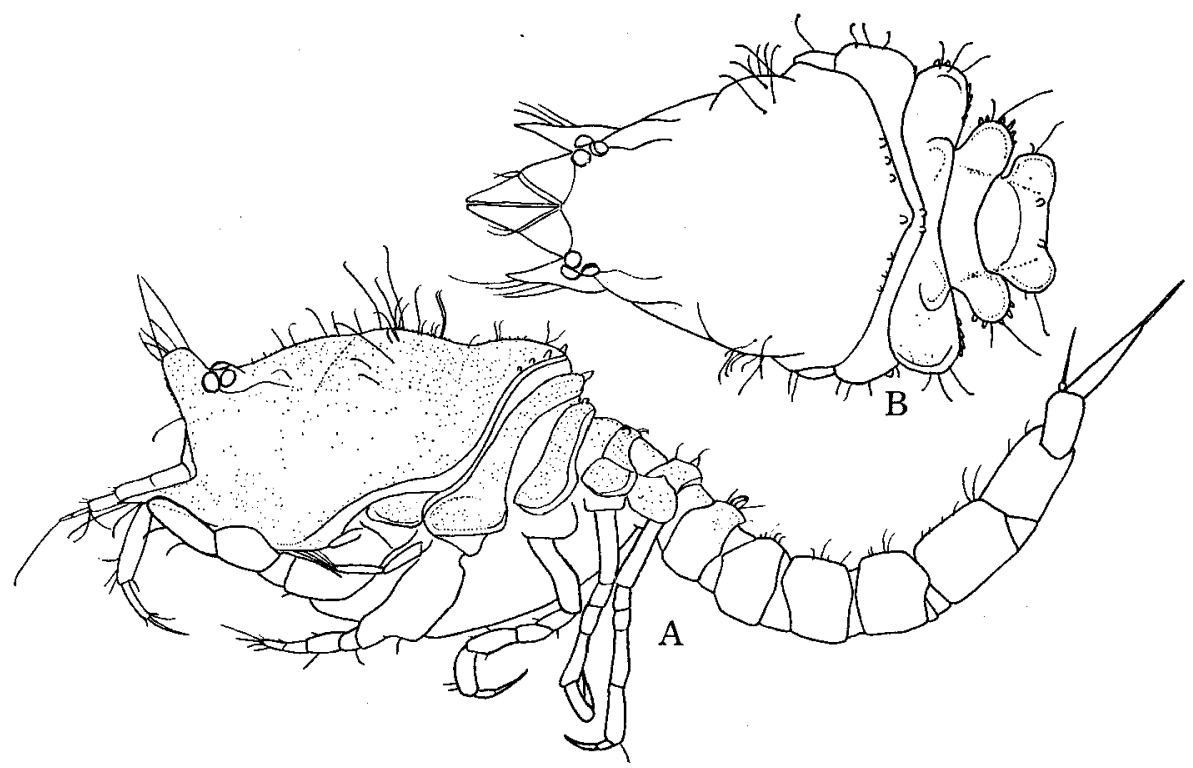

Fig. 16. Nannastacus goniatus sp. nov., type female (length, ca. $1.7 \mathrm{~mm}$ ). A : lateral view. B : anterior portion of body, from above.

The first joint of peduncle of antennule is much longer than the second and third combined and nearly two and two-thirds times as long as the second. The third is much longer than the second.

The basis of third maxilliped without an exopod is three-fifths as long as the remaining distal joints together. The ischium is very short. The propodus is a little longer than the carpus. The dactylus is about two-thirds as long as the propodus.

The basis of first peraeopod with an exopod is very short and less than onehalf as long as the remaining distal joints together, The propodus is much shorter than the carpus and much less than twice as long as the dactylus. 
The second peraeopod with an exopod is about two-thirds as long as the first. The basis is nearly as long as the remaining distal joints together. The carpus is longer than the merus, as long as the propodus and dactylus combined and as long as the longest distal spine of dactylus. The dactylus is short and broad, and a little longer than the propodus.

The carpus of fifth peraeopod is longer than the propodus, which is as long as the dactylus.

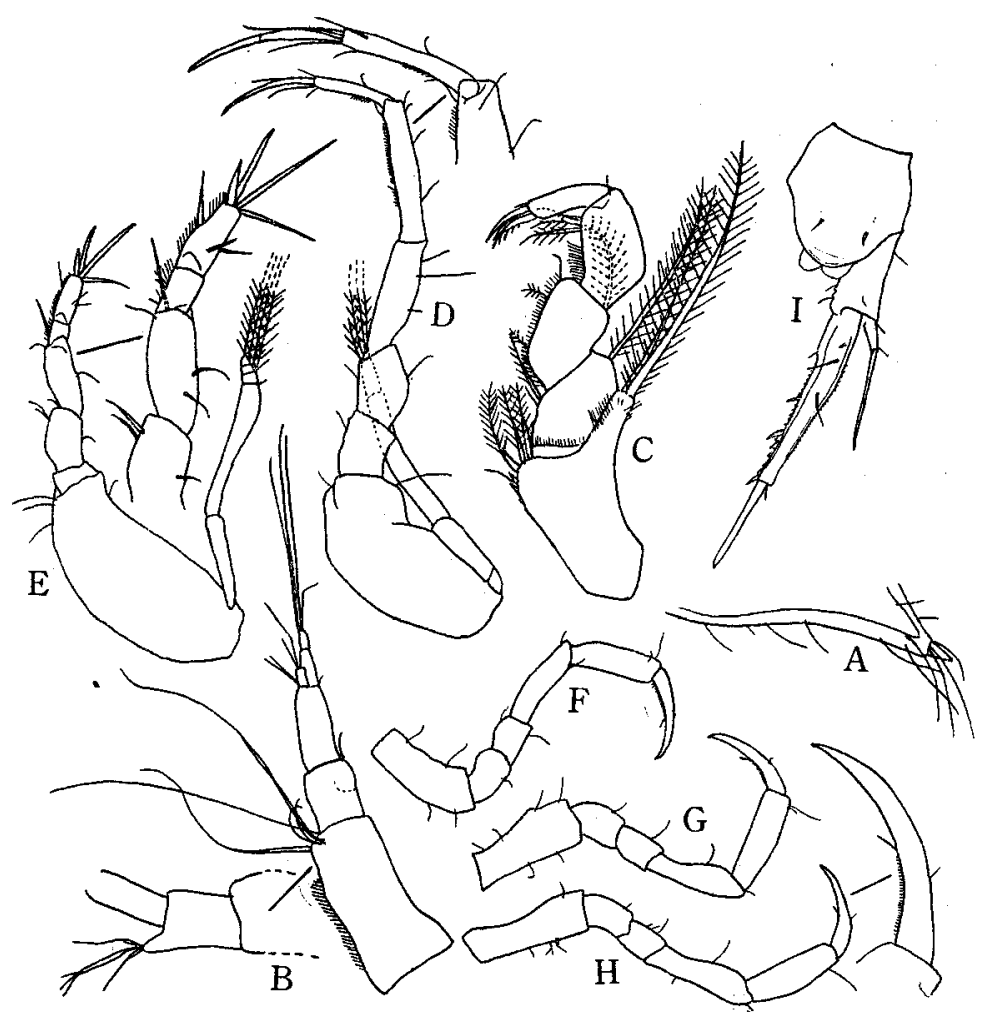

Fig. 17. Nannastacus goniatus sp. nov., type female. A : antero-lateral angle, lateral view. $\mathrm{B}:$ antennule. $\mathrm{C}$ : third maxilliped. $\mathrm{D}-\mathrm{H}$ : first to fifth peraeopods. I : uropod with sixth abdominal segment.

The peduncle of uropod is two-thirds as long as the sixth abdominal segment and nearly one-half as long as the endopod (exclusive of its terminal spine). The exopod is one-seventh as long as the endopod and furnished with a long terminal spine, which is about one-half as long as the endopod. The endopod is armed with three spaced spines on the spinulous inner edge, all equal in length, and with a termianl spine half the length of the ramus.

Remarks: The new species is very closely related to $N$. gibbosus Calman, $N$. reptans Calman and $N$. minor Calman from Gulf of Siam (CALMaN '11). It 
differs from $N$. gibbosus and $N$. minor by the different proportions of the joints of peraeopods and uropod, and from $N$. reptans by having the exopod on the basis of third maxilliped and first two pairs of peraeopods.

It is also very closely related to $N$. jonstoni HALE, $N$. inflatus HALE and $N$. subinflatus HALE from Australia. N. inflatus and $N$. subinflatus are distinguished by the different proportions of the joints of the first peraeopod. In $N$. jonstoni the postero-lateral portion of carapace is somewhat overlapped over the pleural parts of second thoracic segment; the posterior border of carapace have no spiniform granules, and such granules are absent from the lateral borders and from the dorsal surface of the thoracic segments.

Occurrence: 9 ㅇ ( 1 우, type specimen).

10. Nannastacus nyctagineus sp. nov.

(Figs. 18, 19)

Type female specimen (length, about $1.6 \mathrm{~mm}$ ): The carapace is relatively large and robust, nearly three-sevenths of the total length of animal and about one and one-fourth times as long as the width, which is slightly more than one and one-third times as wide as the depth. It is the widest across the branchial regions which are much swollen. The antero-lateral margin is angularly concave at obtuse angle. The antero-lateral angle is well marked, produced and acute. The pseudorostral lobes are directed upwards, the lobes are gaping above and below and not meeting to any appreciable extent. As seen from side the front of the lobes is truncated and armed wih serrations.

The pleural parts and an elevated narrow stripe of the first free thoracic segment is exposed. The second is also elevated and short dorsally, and wider than the carapace. The pleural parts of all the free thoracic segments are expanded laterally. The first four are armed with flattened spines on the lateral borders. On the dorsal surface of the second to fifth there are a pair of spines. The back of fourth and fifth is slightly raised.

The abdomen is one-half of the total length of animal. Each of the first to fourth abdominal segments is short and stout, and about as long as the depth. The fifth is longer than the others. The sixth abdominal segment is slightly longer than the width.

The first joint of peduncle of antennule is longer than the subequal distal two joints combined.

The basis of third maxilliped without an exopod is one-half as long as the remaining distal joints together. There is a long process on the outer distal angle of basis; it is about one-half as long as the basis (including the process). The carpus is a little less than the propodus.

The basis of first peraeopod with an exopod is two-thirds as long as the 
remaining distal joints together. The carpus is nearly one and one-half times as long as the merus and about equal to the propodus in length. The dactylus is much shorter than the propodus.

The second peraeopod with an exopod is about four-fifths as long as the first. The basis is much longer than the remaining distal joints together. The carpus is less than one and one-half times as long as the merus and nearly as long as the propodus and dactylus combined. The dactylus is a little longer than the propodus.

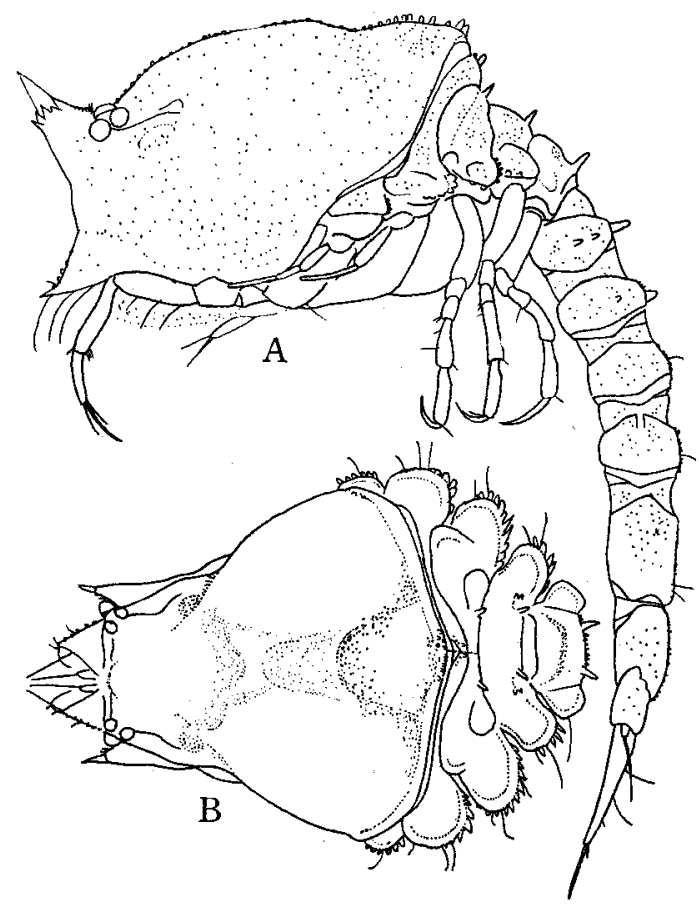

Fig. 18. Nannastacus nyctagineus sp. nov., type female (length, ca. $1.6 \mathrm{~mm}$ ). A : lateral view. B : anterior portion of body, from above.

The carpus of fifth peraeopod is longer than the propodus.

The peduncle of uropod is about two-thirds as long as the last abdominal segment and furnished with two lateral spines on the inner edge. The endopod is about two and one-fourth times as long as the peduncle. There are serrations and four spines on the inner edge and small serrations on the outer and a stout terminal spine, which is about one-half as long as the endopod. The exopod is about one-ninths as long as the endopod and furnished with a long terminal spine, which is much more exceeding the middle of the endopod. 
Remarks: The new species is very like $N$. jonstoni HALE, from which it differs by having no spiniform granules on the dorsal surface of the free thoracic and abdominal segments.

Occurrence: 4 우 (1 9 , type specimen).
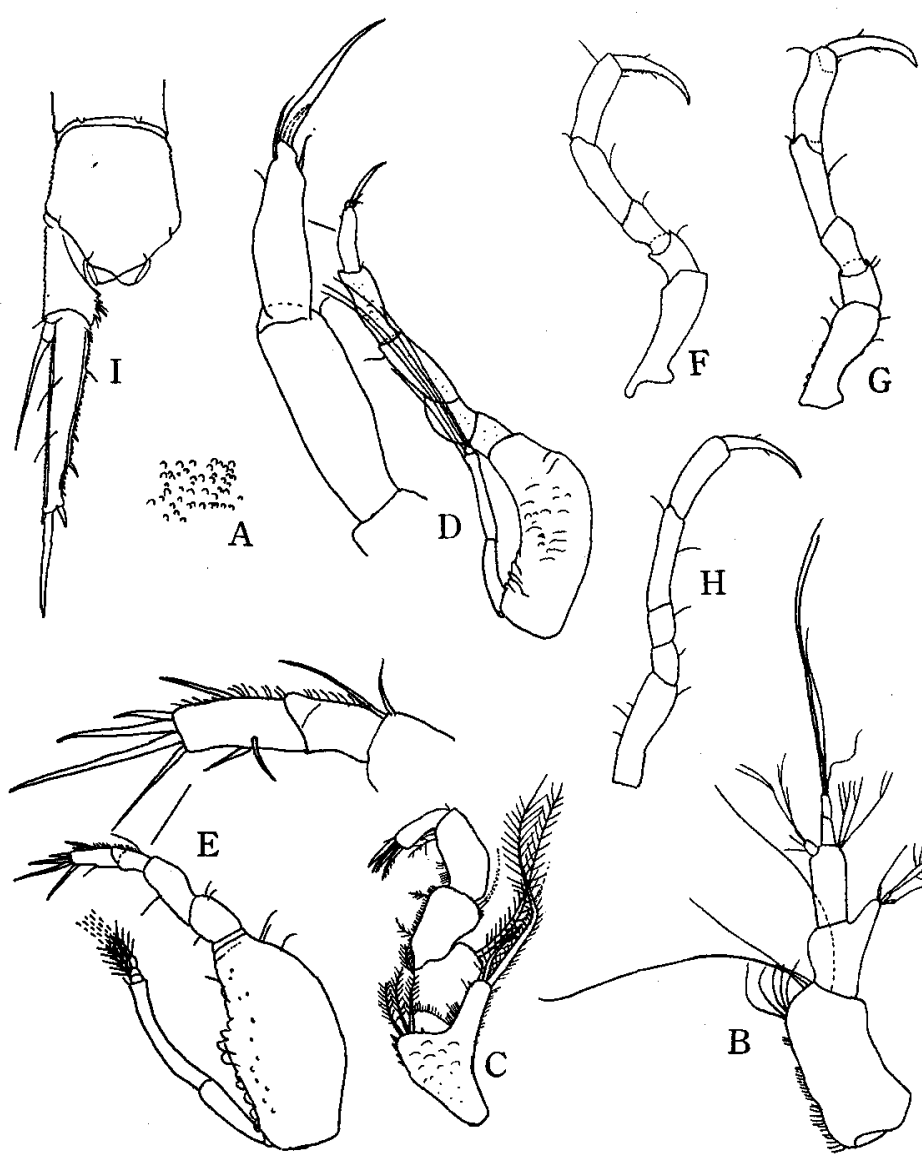

G
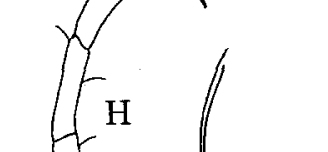

Fig. 19. Nannastacus nyctagineus sp. nov., type female. A : sculpture of carapace. B : antennule. C : third maxilliped. D-H : first to fifth peraeopods. I : uropod with sixth abdominal segment.

\section{Nannastacus pectinatus sp. nov.}

(Figs. 20, 21)

Type male specimen (length, about $1.6 \mathrm{~mm}$ ) : The integument is well calcified. The cephalothorax and the pleon are closely beset with minute spiniform granules and becoming sparser on the telsonic segment. The carapace is depressed, slightly 
less than one and one-third times as wide as the depth and one and two-thirds times as long as the depth; it is nearly three-eighths as long as the total length of animal and a little more than one and one-half times as long as the free thoracic segments together. There are a pair of dorso-median longitudinal rows of spinules. The eyes are widely separated and each is furnished with usual three corneal lenses. The antero-lateral angle is furnished with small spiniform turbercles, one of which is very definitely emphasizes the angle. The anterolateral and branchial regions are a little swollen and a posterior median is a little tumid. The lower border of carapace is entirely smooth. The pseudorostral lobes are subtriangular, widely separated both above and below.

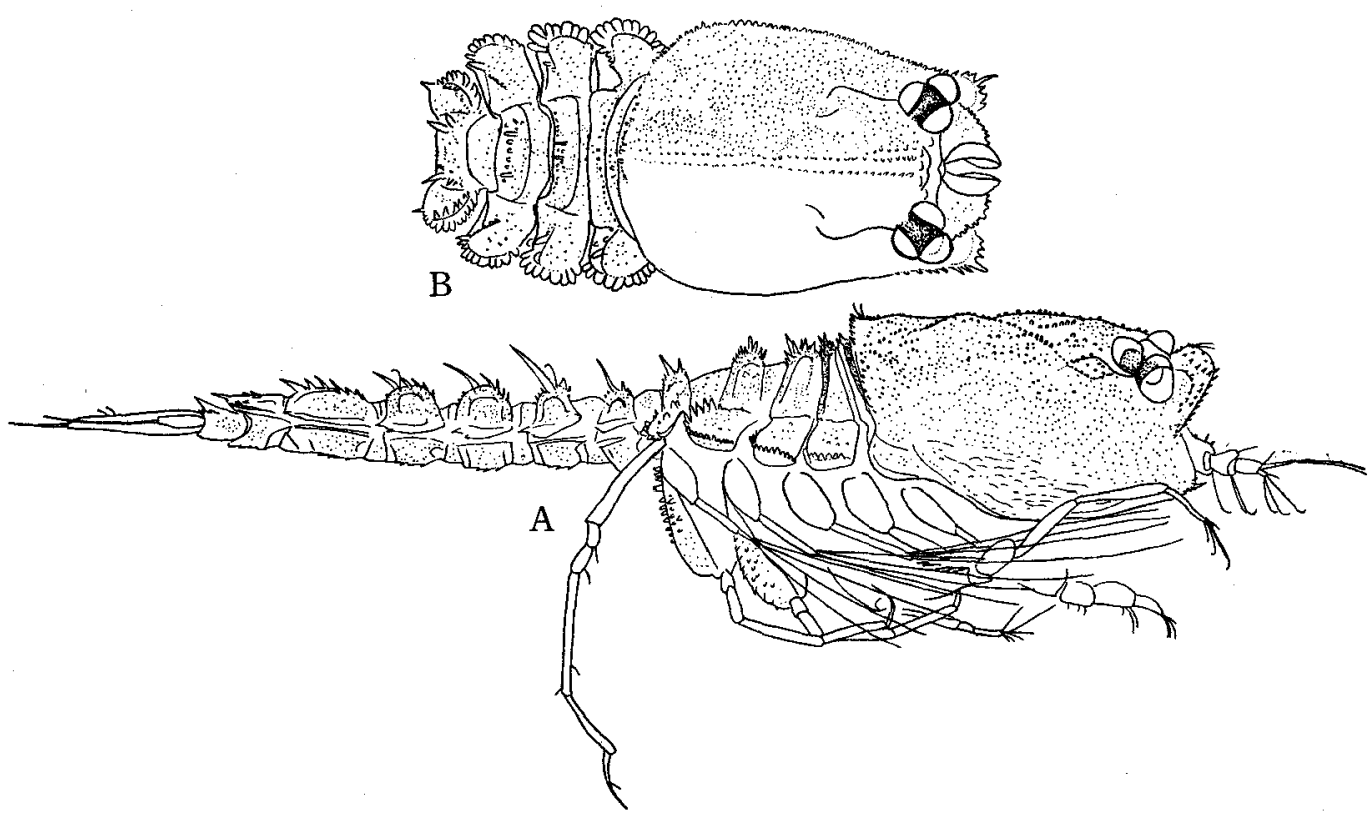

Fig. 20. Nannastacus pectinatus sp. nov., type male (length, ca. $1.6 \mathrm{~mm}$ ). A : lateral view. B : anterior portion of body, from above.

The first free thoracic segment is the shortest and its pleural parts concealed with the postero-lateral parts of carapace. The width of the third and fourth is about as wide as the second, which is less than as wide as the carapace. The pleural parts of the second to fifth segments are margined with flattened hyaline spines. Each of the dorso-median parts of the first to fifth is furnished with pairs of spines and spiniform tubercles.

The first joint of peduncle of antennule is about as long as the subequal distal two joints combined.

The basis of third maxilliped with an exopod is shorter than the remaining distal joints together. The propodus is longer than the carpus. 
The basis of first peraeopod is a little more than three-fifths as long as the remaining distal joints together. The merus is more than one-half as long as the carpus, which is about as long as the propodus. The dactylus is about one-half as long as the propodus.

The second peraeopod is a little longer than two-thirds of the first. The

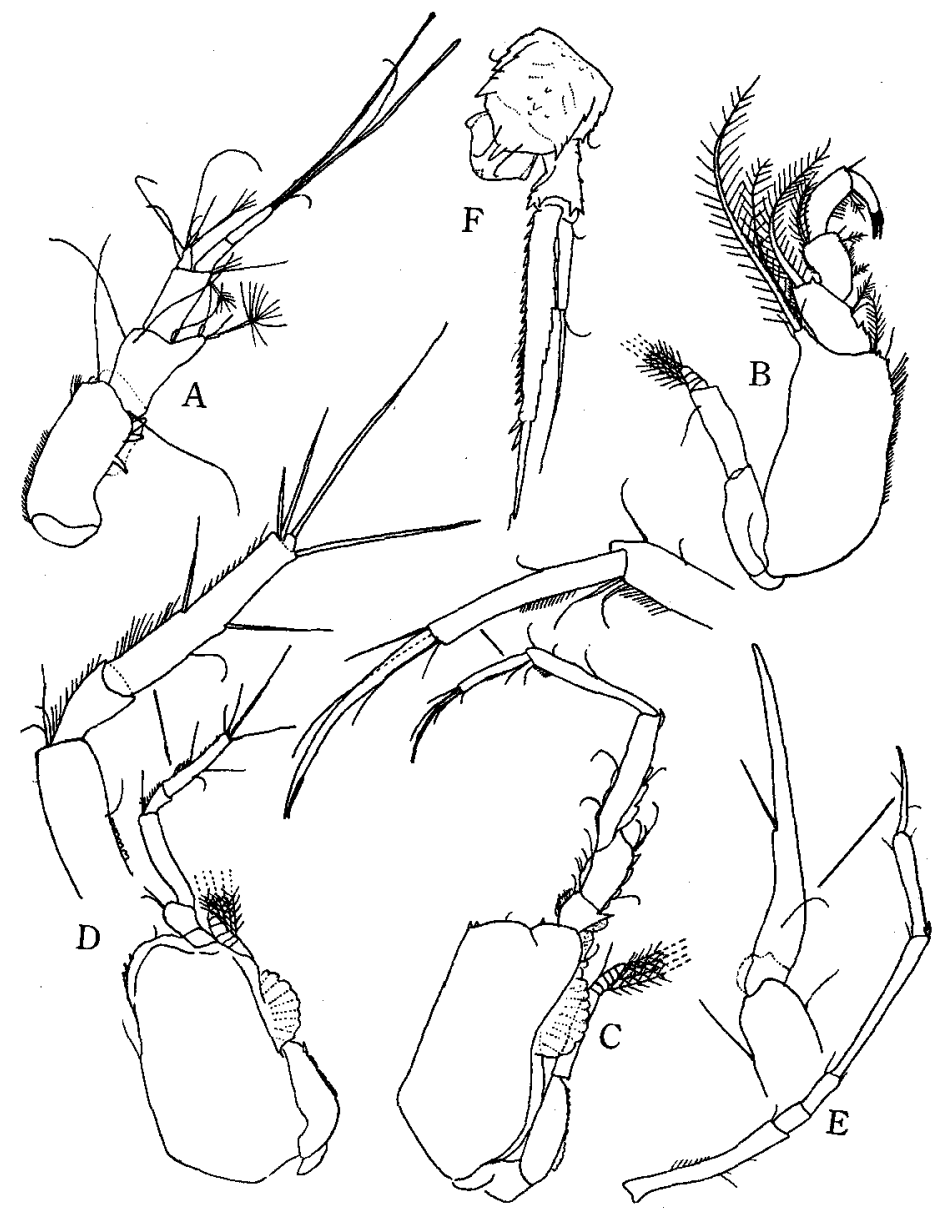

Fig. 21. Nannastacus pectinatus sp. nov,, type male. A : antennule. B : third maxilliped. C-D : first and second peraeopods. E : uropod with sixth abdominal segment.

basis is about as long as the remaining distal joints together. The carpus is slightly less than three times as long as the merus, and slightly less than the propodus and dactylus combined. The longest distal spine of dactylus is longer than the dactylus.

The carpus of the fifth peraeopod is about one and one-half times as long as the propodus. 
The peduncle of uropod is two-thirds as long as the last abdominal segment and slightly more than one-third as long as the endopod (exclusive of its distal spine). The exopod is nearly one-half as long as the endopod and furnished with its terminal spine, which is beyond the distal end of the latter and reaching the level about half the length of terminal spine of the endopod. The endopod is furnished with two unequal short spines on the inner side and a long spine (which is slightly less than one-half as long as the ramus) and both lateral margins are serrate for whole length.

Remarks: The new species is related to $N$. ossiani Stebbing (Stebbing 1900) and $N$. stephenseni FAGE (FAGE '45). Those are distinguished from the new species as follows: In $N$. ossiani the surface of carapace is covered with hexagonal or scale-like reticulations: $N$. stephenseni has the relatively longer peduncle of uropod and the shorter endopod.

It is most closely related to N. ungiculatus BATE (FAGE '51) and $N$. stebbingi Calman (CAlman '04). From N. ungiculatus it differs by having many minute spiniform granules on the surface of the carapace and relatively longer exopod; from $N$. stebbingi it is distinguished by having no conspicuous rounded knob-like prominence located a little behind the eyes, no group of three curved spines on the antero-lateral margin of carapace and the relatively longer exopod (exclusive of the terminal spine). It also differs from $N$. stebbingi var. deformis FAGE (FAGE '45) by having no triangular large protuberance on the posterior portion of carapace.

Occurrence: $40 \AA(1 \delta$, type specimen).

12. Nannastacus spinulosus sp. nov.

(Figs. 22, 23)

Type adult male specimen (length, about $1.6 \mathrm{~mm}$ ): The carapace is about one and one-fifth times as wide as the depth and nearly three-fifths as long as the depth; it is nearly one-fifth as long as the total length of animal and slightly less than twice as long as the free thoracic segments together. There are a pair of dorso-median longitudinal rows of spinules. The eyes are widely separated, each is furnished with three corneal lenses. The antero-lateral margin is angularly concave and beset with spinules and with a group of about fuor spines, one of which is stout. The antero-lateral angle and the distal portion of lateral or lower margin is furnished with spinules. The pseudorostral lobes are very short and upterned.

The first free thoracic segment is almost concealed. The second to fifth segments are spinulous and furnished with rows of spines on the dorsal surface; the pleural parts are somewhat expanded laterally and margined with crests of 
acute spines. The second to fourth are about as wide as the carapace and subequal in length. The fifth is a little smaller than the others.

Each of all the abdominal segments is spinulous, subequal in length and provided with rows of spines on the dorsal surface and with well developed antennal groove on each side.

The first joint of peduncle of antennule is more than the subequal distal two joints together.

The basis of third maxilliped with an exopod is about one and one-fifth times as long as the remaining distal joints together. The carpus is about as long as the propodus.

The basis of first peraeopod is nearly two-thirds as long as the remaining distal joints together. The merus is one-half as long as the carpus, which is as

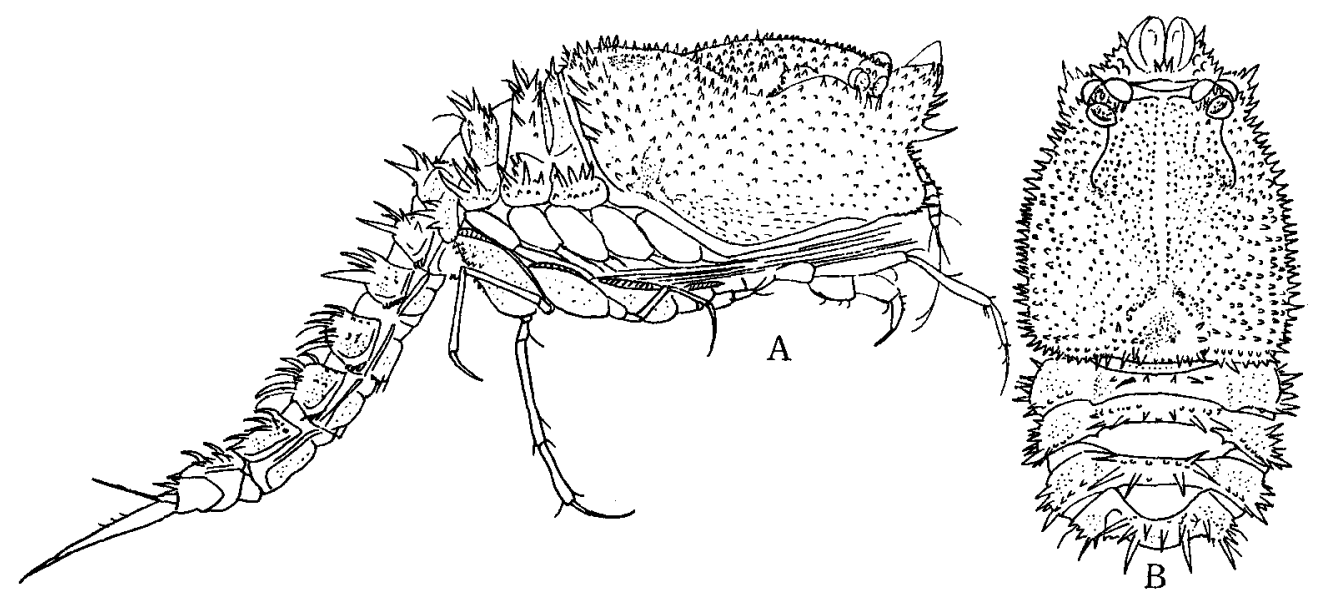

Fig. 22. Nannastacus spinulosus sp. nov., type male (length, ca. $1.6 \mathrm{~mm}$ ). A : lateral view. B : anterior portion of body, from above.

long as the propodus. The dactylus is a little more than one-half as long as the propodus.

The second peraeopod is longer than two-thirds of the first. The basis is much longer than the remaining distal joints together. The carpus is twice as long as the merus and much less than the propodus and dactylus together. The longest distal spine of dactylus is nearly as long as the propodus and dactylus combined.

The carpus of fifth peraeopod is much less than twice as long as the propodus.

The peduncle of uropod is about two-thirds as long as the last abdominal segment and one-third as long as the endopod, which is nearly two and one-third times as long as the exopod. The peduncle is furnished with serrations on both edges and a tooth on the inner termianl angle. The endopod is serrated and furnished with a spine on each edge, and a stout and two short spines on the distal end. The long stout spine of the endopod is a little less than one-half as 
long as the endopod. The exopod has a short and a long distal spines. The long distal spine is reaching the level just beyond the distal end of endopod.

Remarks: The new species is closely related to $N$. ungiculatus $\mathrm{B}_{\mathrm{ATE}}$ and $N$. pectinatus. It differs from the last-named two by having the carapace with

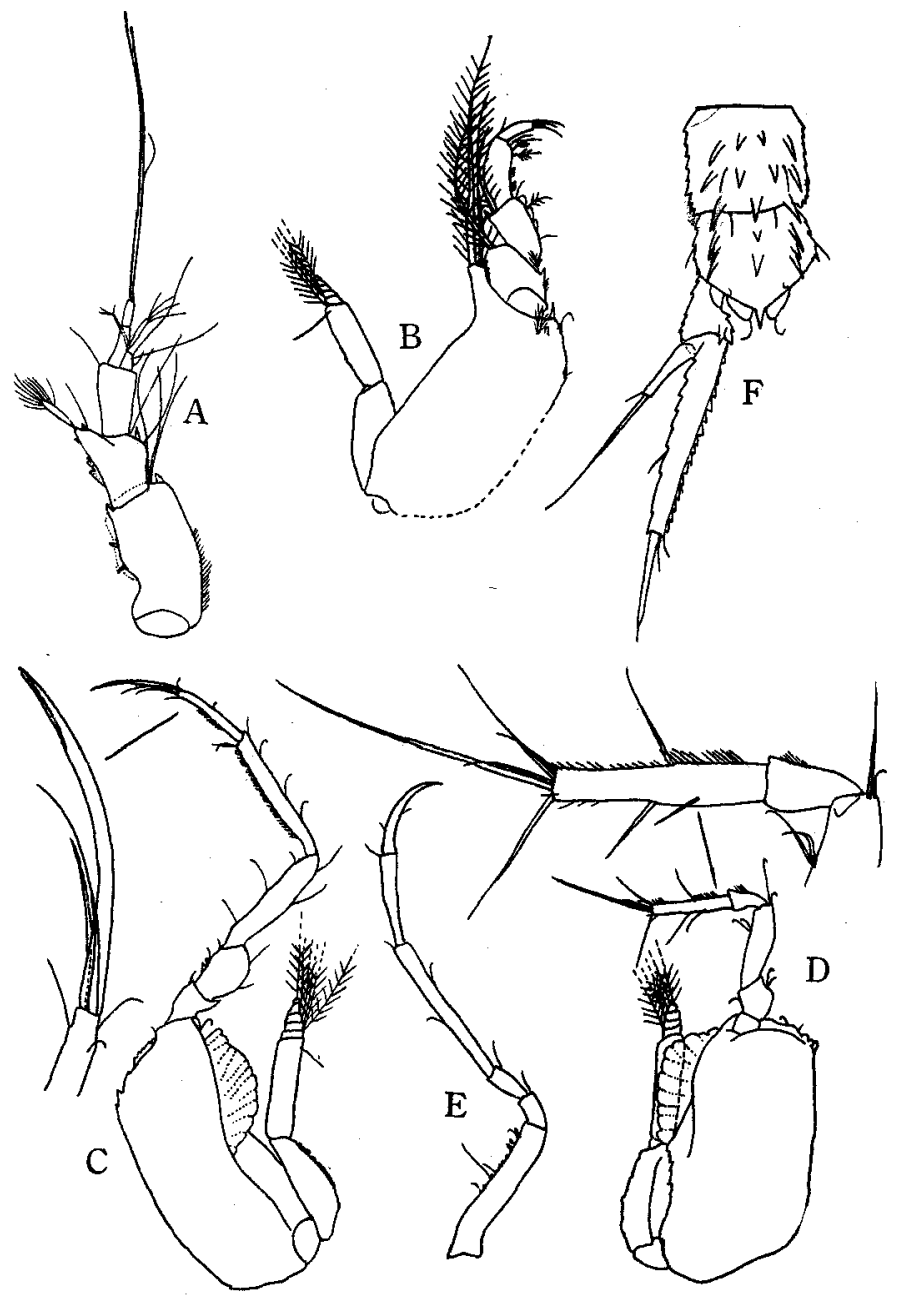

Fig. 23. Nannastacus spinulosus sp. nov., type male. A : antennule. $B$ : third maxilliped. $C-D$ : first and second peraeopods. $\mathrm{E}$ : fifth peraeopod. $\mathrm{F}$ : uropod with fifth and sixth abdominal segments.

many spinules and a group of spines on the antero-lateral margin.

It is perhaps most closely related to $N$. stebbingi Calman (CALMAN '04) from Gulf of Mannar (depth, 2 fathoms) in having a group of spines on the anterolateral margin of carapace, but the carapace of it is more spinulous and the 
pleural parts of the second to fifth free thoracic segments have the crests of acute spines.

Occurrence: $146 \hat{\delta}(1 \hat{\delta}$, type specimen).

13. Nannastacus spinosus sp. nov.

(Figs. 24, 25)

Type adult female specimen with marsupium (length, about $1.4 \mathrm{~mm}$ ): The integument is calcified and covered with many spinules and delicate bristle spines. The carapace is a little less than three-sevenths of the total length of animal, nearly one and two-thirds times as long as the free thoracic segments together and about one and one-half times as long as the depth, which is nearly threefourths as deep as the width. Seen from the above, it is the widest across the branchial regions which are much inflatted and provided with a distinct median gutter between them. On the posterior portion there is a round median elevation. Seen from the side, the tumidities result in an uneven dorsal outline. The pseudorostal lobes are short and upterned, both are a little separated and armed with spines. On the under side there are three conspicuous spines. The anterolateral margin is deeply and angularly concave. The antero-lateral angle is produced to form an acute tooth and armed with spinules and spines.

The first free thoracic segment is exposed as a very narrow stripe. The first three segments are nearly as wide as the carapace. The fourth and fifth are about one-half as wide as the second. Their pleural parts are expanded and armed with larger spines. A large pleural spine on the fifth is longer than that of the others and about as long as the width of the segment The dorsal pair of spines on the second and third are not larger than the pleural spines, the dorsal spines on the fourth are longer and such spines on the fifth are as long as the longest spine of the first to fourth abdominal segments.

The first to fifth abdominal segments are successively increase in size. Each of them is furnished with rows of six or fourteen dorsal and dorso-lateral spines, which is successively decrease in size. The sixth segment is provided with a pair of spines on the dorsal surface, such spines on poth sides and a short median spine on the distal end.

The first joint of peduncle of antennule is one and one-half times as long as the third, which is about as long as the second. The main flagellum is twojointed and the first is as long as the second. The accessory flagellum is singlejointed and shorter than the first joint of peduncle.

The basis of third maxilliped is a little less than three-fourths as long as the remaining distal joints together. The ischium is one-half as long as the merus. The carpus is longer than the merus and shorter than the propodus. The dactylus is about two-thirds as long as the propodus. 
The basis of first peraeopod is nearly three-sevenths as long as the remaining distal joints together. The merus is one and one-half times as long as the ischium. The carpus is one and three-fourths times as long as the merus and a little shorter than the carpus. The dactylus is more than one-half as long as the propodus.

The basis of second peraeopod is more than two-thirds as long as the remaining distal joints together. The dactylus is a little shorter than the carpus and provided with small spines and two long spines on the lateral borders. There

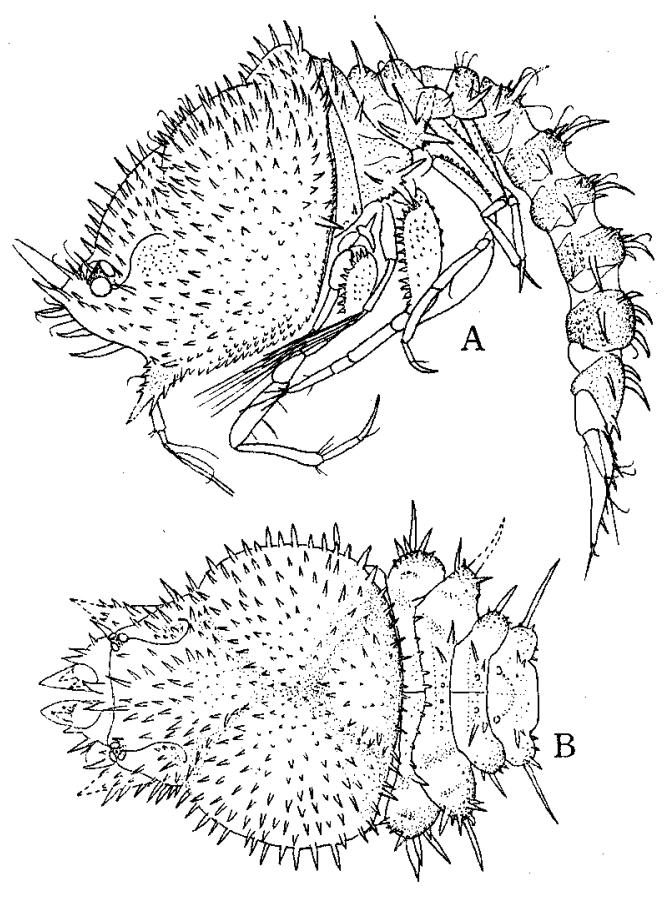

Fig. 24. Nannastacus spinosus sp. nov., type female with marsupium (length, ca. $1.4 \mathrm{~mm}$ ). A : lateral view. B : anterior portion of body, from above.

are four long terminal spines, of which the longest is much more than the dactylus The propodus is two-fifths as long as the carpus.

The third peraeopod is about one and one-fourth times as long as the second. The basis is slender and two and one-fourth times as long as the remaining distal joints together. The propodus is four-fifths as long as the carpus. The dactylus is a little less than one-half as long as the propodus and has a stout terminal claw as long as the joint.

The fourth peraeopod is longer than the third and as long as the fifth. The 


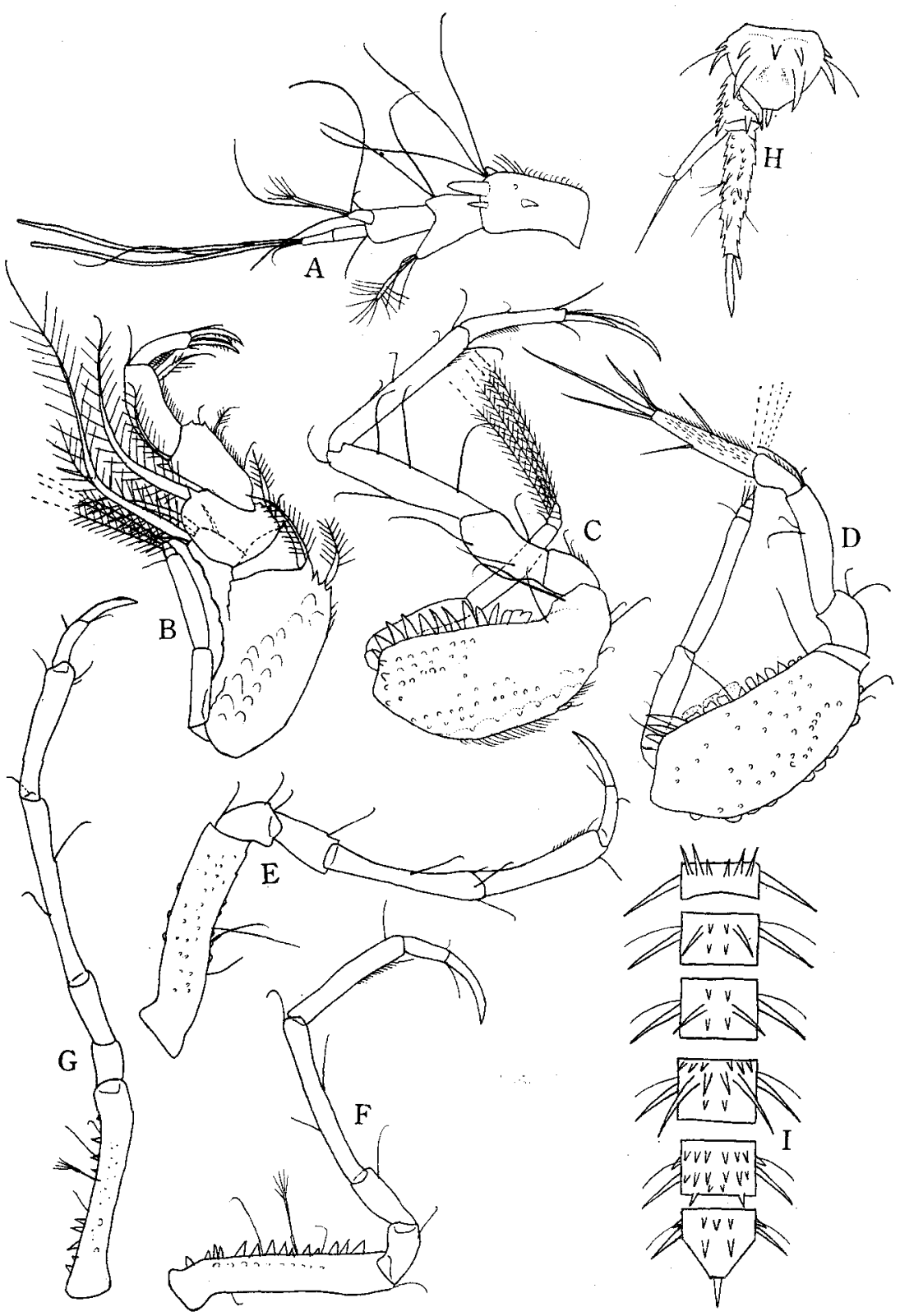

Fig. 25. Nannastacus spinosus sp. nov., type female with marsupium. A : antennule. B : third maxilliped. $C-G$ : first to fifth peraeopods. $\mathrm{H}$ : uropod with sixth abdominal segment. I : arrangement of dorsal spines on the abdominal segments. 
basis is about two-fifths as long as the remaining distal joints together. The ischium is shorter than the merus. The propodus is more than three-fourths as long as the carpus and as long as the ischium and merus combined. The dactylus is nearly one-third as long as the propodus and has a short claw, which is one and one-half times as long as the joint.

The fifth peraeopod is very like the fourth, but the basis is more slender than that of the fourth. The propodus is slightly more than two-thirds as long as the carpus. The dactylus is more than one-third as long as the propodus and has a stout claw as long as the joint.

The peduncle of uropod is nearly two-thirds as long as the last abdominal segment and provided with spines on both edges and on the terminal end. The endopod is two and one-half times as long as the peduncle and furnished with serrations on both edges, spines and about four setae on the dorsal surface and two stout spines on the terminal end. The exopod is a little more than one-half as long as the endopod and furnished with a long terminal spine nearly as long as itself.

Remarks: The new species is easily distinguished from $N$. erinaceus $Z_{\text {IMMER }}$ (Zimmer '13), N. ungiculatus (BAte) (FAGe '51), N. hanseni Calman (CAlmaN '05b) and $N$. ossiani Stebbing (STEbBIng 1900) by having the different armatures of spines.

It is very closely related to Schizotrem aculeata HALE from Australia (HALE '45), from which it differs by having the narrowly separated pseudorostal lobes. The genus Schizotrema is characterized by having the widely sepatated pseudorostral lobes.

It reveals the close affinty between Nannastacus and Schizotrema that the pseudorostral lobes of $N$. spinosus and $N$. hanseni CALman (CALMan '05b and F AGE '45) are somewhat intermediate conditions.

Occurrence: 3 우 (1 ㅇ, type specimen).

14. Cumella glaberata sp. nov.

(Figs. 26, 27)

Type male specimen (length, about $2.5 \mathrm{~mm}$ ); The carapace is a little depressed. The length is as long as the free thoracic segments and first two abdominal segments together, less than one-third of the tolal length of animal, and nearly twice as long as the depth, which is less than the width. On the dorsal surface there is a low median carina. The antennal notch is shallowly concave. The antero-lateral corner is rounded, obtusely angular and beset with a spine on the lateral border. The pseudorostral lobes are meeting in front for a distance equal to the length of ocular lobe and seen from the side it is very obliquely truncated and upterned. The ocular lobe is much wider than its length and with furnished seven eyes.

The first free thoracic segment is exposed dorsally and concealed the lower 
part of side by the anterior pleural lobe of the second. The pleural part of the third to fifth are expanded and slightly produced. The second is a little less than as wide as the carapace. On the fifth segment there is a faint median carina.

The first four abdominal segment are about subequal in length and each of them is shorter than the fifth. The fifth is shorter than twice as long as its width. The sixth abdominal segment is longer than the fifth, much less than twice as long as its width. The terminal end is widely truncated and furnished with a median round tooth. On the dorsal surface of each of all the abdominal segments there is a faint median carina.

The first joint of peduncle of antennule is much shorter than the third. The second is about as long as the third. The first joint of main flagellum is much longer than the second. The accessory flagellum is very minute and single-jointed.

The flagellum of antenna is reaching the end of second abdominal segment.

The basis of third maxilliped is a little longer than the remaining distal joints

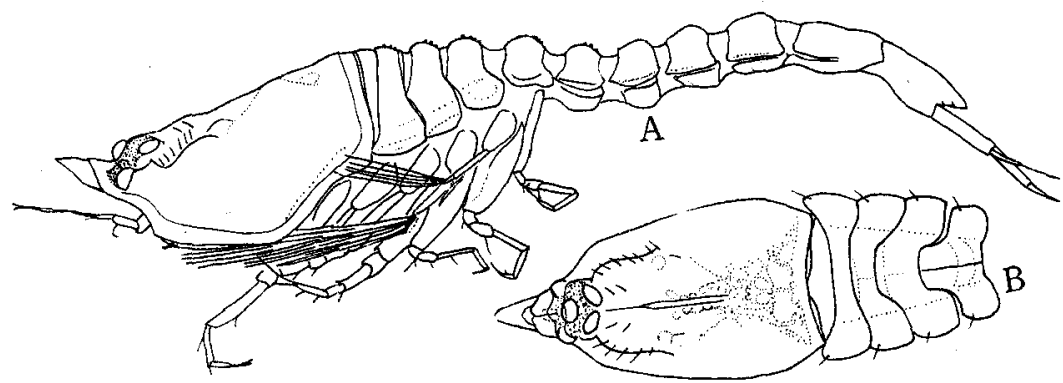

Fig. 26. Cumella glaberata sp. nov., type male (length, ca. $2.5 \mathrm{~mm}$ ). A : lateral view. B : anterior portion of body, from above.

together. The merus is as long as the carpus. The outer angle of merus is produced and furnished with a long plumous hair. The dactylus is about one-half as long as the propodus, which is nearly one and one-half times as long as the carpus.

The basis of first peraeopod is about four-fifths as long as the remaining distal joints together. The merus is as long as the ischium and slightly less onehalf as long as the carpus. The carpus is nearly as long as the propodus and dactylus combined. The dactylus is much longer than one-half as long as the propodus.

The basis of second peraeopod is about as long as the remaining distal joints together. The ischium is very short. The carpus is a little more than as long as the dactylus. The dactylus is about twice as long as the propodus and furnished with a terminal spine equal in length to itself.

The carpus of fifth peraeopod is more elongate than those in the preceding peraeopods, more than twice as long as the merus and nearly one and two-thirds as long as the propodus.

The peduncle of uropod is five-sixths as long as the sixth abdominal segment 
and slightly longer than the endopod (exclusive of its terminal spine). The inner edge is spinulose and armed with six large spaced spines, successively decreasing in length towards the rear. The exopod is one-half as long as the endopod and furnished with a long terminal spine. The endopod has many spinules and six spaced spines on the inner edge, about five spinules on the proximal outer edge and a short roubust spine on the distal end.

Remarks: The new species resembles C. pygmaea SARS (SARs 1879; FAGE '51) and C. limicola SARS (SARS 1879 ; BăCESCU '51; FAGE '51). Those differ by having the uropod with relatively long peduncle and with shorter endopod.

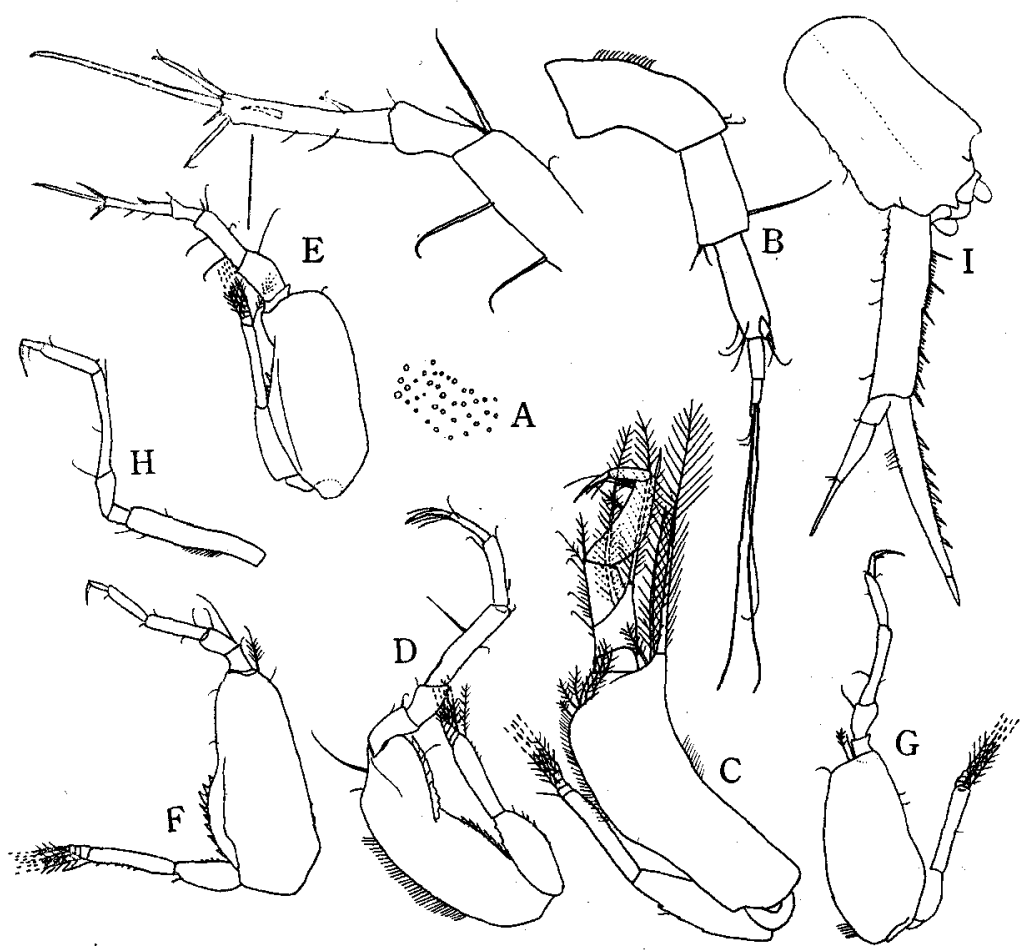

Fig. 27. Cumella glaberata sp. nov., type male. A : sculpture of carapace. B : antennule. $\mathrm{C}$ : third maxilliped. $\mathrm{D}-\mathrm{H}$ : first to fifth peraeopods. I : uropod with sixth abdominal segment.

It is perhaps most closely related to C. serrata Calman (CALman '11) from Danish West Indies and C. indosinica ZIMMER (ZIMMER '52) from Vietnam in having the eyes with large lenses. In $C$. serrata the fifth abdominal segment is longer than the sixth and the peduncle of uropod is more than one and one-half times as long as the sixth abdominal segment. The carapace of $C$. indosinica is as long as the free thoracic segments and the first three abdominal segments together and the peduncle of uropod is longer than the sixth abdominal segment.

Occurrence: $69 \hat{\text { o }}$ ( $1 \hat{o}$, type specimen). 


\section{Cumella scabera sp. nov.}

(Figs. 28, 29)

Type adult male specimen (length, about $1.9 \mathrm{~mm}$ ): The carapace is nearly one-third of the total length of animal, one and one-half times as long as the free thoracic segments together and one and four-fifths times as long as the width, which is about as wide as the depth. Seen from above it is the widest across the one-third anterior regions, which are somewhst swollen and beset with a longitudinal row of four small median teeth; on the middle oprtion there is a little depressed area. On the lateral and hind margin it is defined with a ridge,

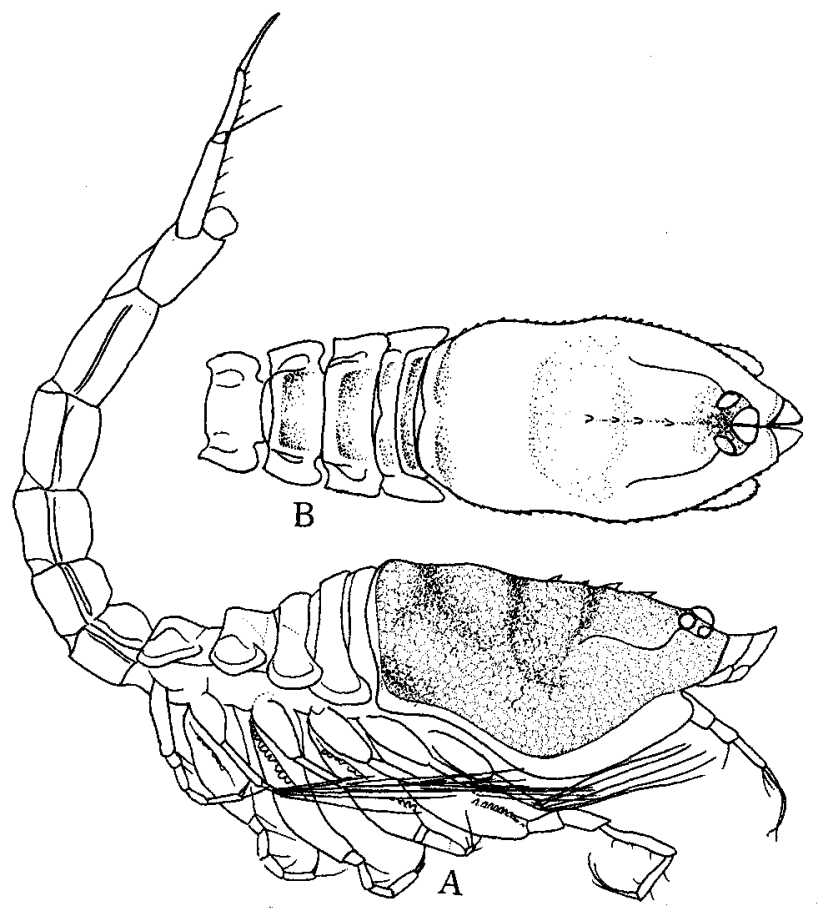

Fig. 28. Cumella scabera sp. nov., type male. (length, ca. $1.9 \mathrm{~mm}$ ). A : lateral view. B : anterior portion of body, from above.

which is much stronger at the anterior half of the lateral margin. The ocular lobe is twice as wide as the length and beset with eyes. The pseudorostral lobes are truncated and meeting in front for a distance about equal to one-half the length of ocular lobe. The antennal notch is angularly concave and the antero-lateral corner is rounded.

The first free thoracic segment is exposed as a narrow stripe. The second is wider than the others and twice as long as the first. The second to fifth segments are successively decreased in width. The last three segments are subequal in length. 
The first joint of peduncle of antennule is one and one-third times as long as the second, which is slightly shorter than the third. The main flagellum is

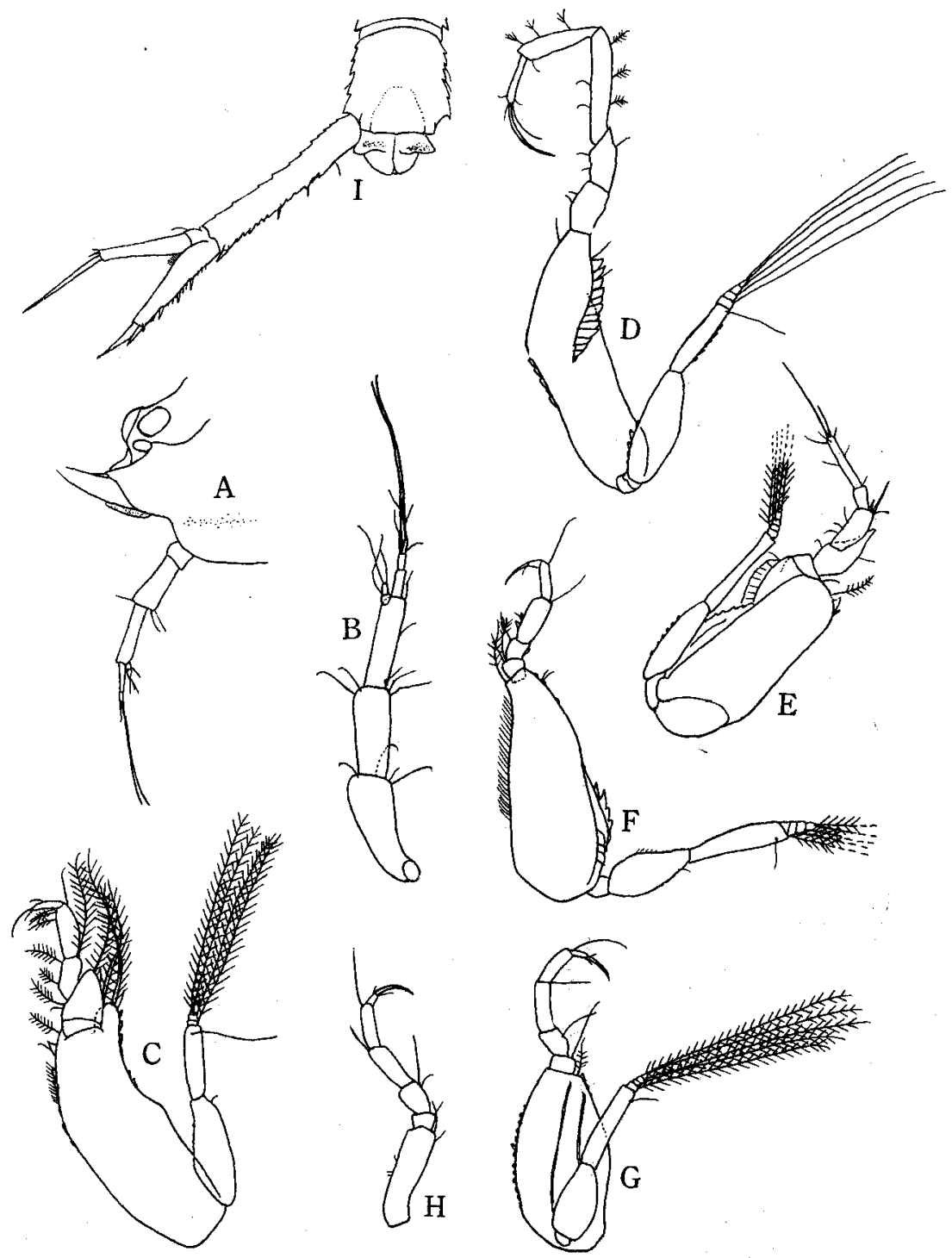

Fig. 29. Cumella scabera sp. nov., type male. A : anterior portion of carapace, lateral view. $B$ : antennule. $C$ : third maxilliped. $D-H$ : first to fifth peraeopods. I : uropod with sixth abdominal segment.

three-jointed, of which the first is longer than the second. The third is about as long as the second. The accessory flagellum is minute and two-jointed.

The basis of third maxilliped is a little less than one and two-thirds times 
as long as the remaining distal joints together and the external angle is developed into a process about one-eighth as long as itself. The ischium is very short. The merus is robust and longer than the carpus, which is much shorter than the propodus.

The basis of first peraeopod is slightly less than five-sixths as long as the remaining distal joints together. The ischium is shorter than the merus, which is about one-half as long as the carpus. The propodus is slightly less than threefourths as long as the carpus. The dactylus is a little less than two-thirds as long as the propodus and has a curved terminal spine much longer than itself.

The basis of second peraeopod is one and one-fourth times as long as the remaining distal joints together. The merus is about one and one-half times as long as the carpus and its inner angle is developed into a stout process about one-half as long as itself. The propodus is about as long as the carpus. The dactylus is longer than the carpus and has a long terminal seta as long as the datylus and propodus together.

The basis of third peraeopod with an exopod is stout and a little more than one and one-half times as long as the remaining distal joints together. The carpus is twice as long as the merus, which is subequal to the ischium. The propodus is three-fourths as long as the carpus. The dactylus is one-third as long as the propodus and furnished with a long terminal spine about twice as long as itself.

The basis of fonrth peraeopod with an exopod is stout and nearly one and one-fifth times as long as the remaining distal joints together. The ischium is one-half as long as the merus, which is about one-half as long as the carpus. The propodus is shorter than the carpus. The dactylus is slightly less than onehalf as long as the propodus and furnished with a long terminal spine.

The basis of fifth peraeopod is slender and two-thirds as long as the remaining distal joints together. The carpus is as long as the ischium and merus combined and slightly longer than the propodus. The dactylus is about one-third as long as the propodus and furnished with a long terminal spine about three times as long as itself.

The last abdominal segment is as long as the width and serrated on both edges. The peduncle of uropod is one and three-fourths times as long as the last abdominal segment and furnished with serrations on both edges and three setae on the inner. The endopod is a little less than two-thirds as long as the peduncle and armed with spinules and spaced three spines on the inner edge and a stout and a short spines on the distal end. There are a group of spinules on the proximal portion of the outer edge. The exopod is about as long as the endopod and has a long terminal spine about as long as itself and two short spines.

Remarks: The new species resembles C. pygmaea SARS (SARs 1879 and 1900; FAGE '51) from Europian saes, from which it is easily distinguished by having the carapace with the greatest width across the anterior third and with a longitudinal 
row of four small median teeth and the exopod about as long as the endopod (exclusive of the terminal spine).

Occurrence: $5 \sigma^{\pi}\left(1 \sigma^{\pi}\right.$, type specimen).

16. Cumella arguta sp. nov.

(Figs. 30, 31)

Adulty type female specimen with marsupium (length, about $1.8 \mathrm{~mm}$ ): The carapace is nearly one-third of the total length of animal and one and one-half times as long as the width, which is three-fourths as wide as the depth. The antero-lateral regions are somewhat swollen, there is a noticeable lateral depression between these tumidities and the swollen branchial areas. There are a fine median carina for the whole length and three median teeth. As seen from the side the

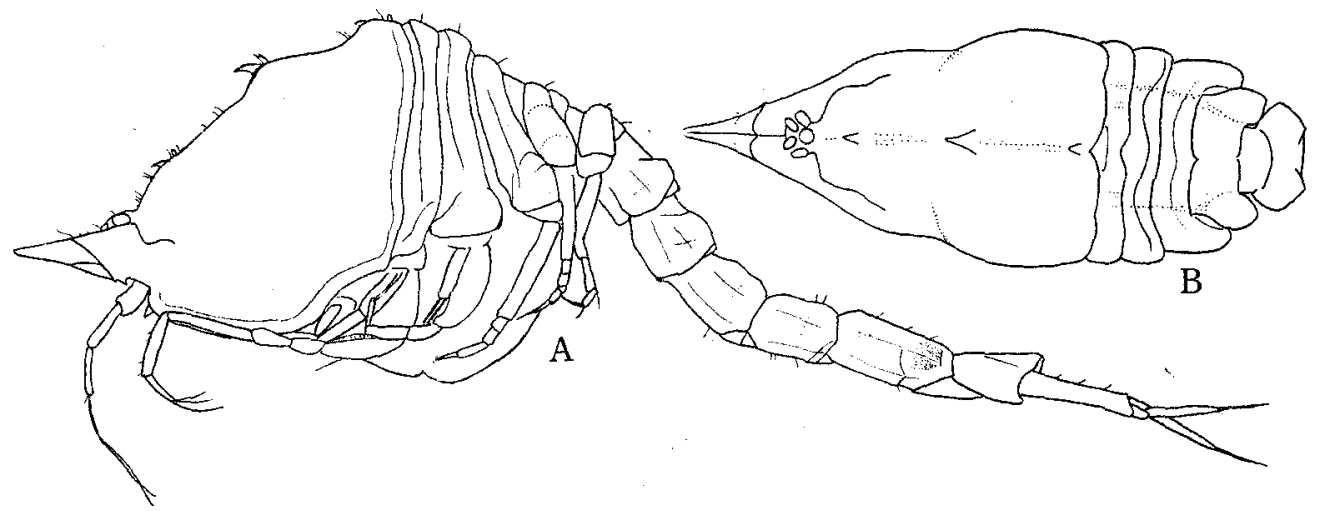

Fig. 30. Cumella arguta sp. nov., type female (length, ca. $1.8 \mathrm{~mm}$ ). A : lateral view. $B$ : anterior portion of body, from above.

dorsal outline is uneven. The pseudorostral lobes are pointed in front, very obliquely as seen from the side, and truncated as from above, and meeting infront of the ocular lobe for a distance about equal to the length of ocular lobe. The antennal notch is deeply concave. The antero-lateral angle is rounded and furnished with a tooth.

The combined length of free thoracic segments is as long as the carapace. The first segment is exposed. The pleural parts of the segments are a little expanded laterally. The first three segments are relatively large, aproximately as wide as the carapace. The fourth is about two-thirds as wide as the carapace. The fifth is three-fourths as wide as the second.

The first joint of peduncle of antennule is shorter than the second, which is as long as the third. The main flagellum is two-thirds as long as the third joint 
of peduncle and three-jointed. The accessory flagellum is one-third as long as the main flagellum and two-jointed.

The basis of third maxilliped with an exopod is one and one-fourth times as long as the remaining distal joints together. The merus and the carpus with a

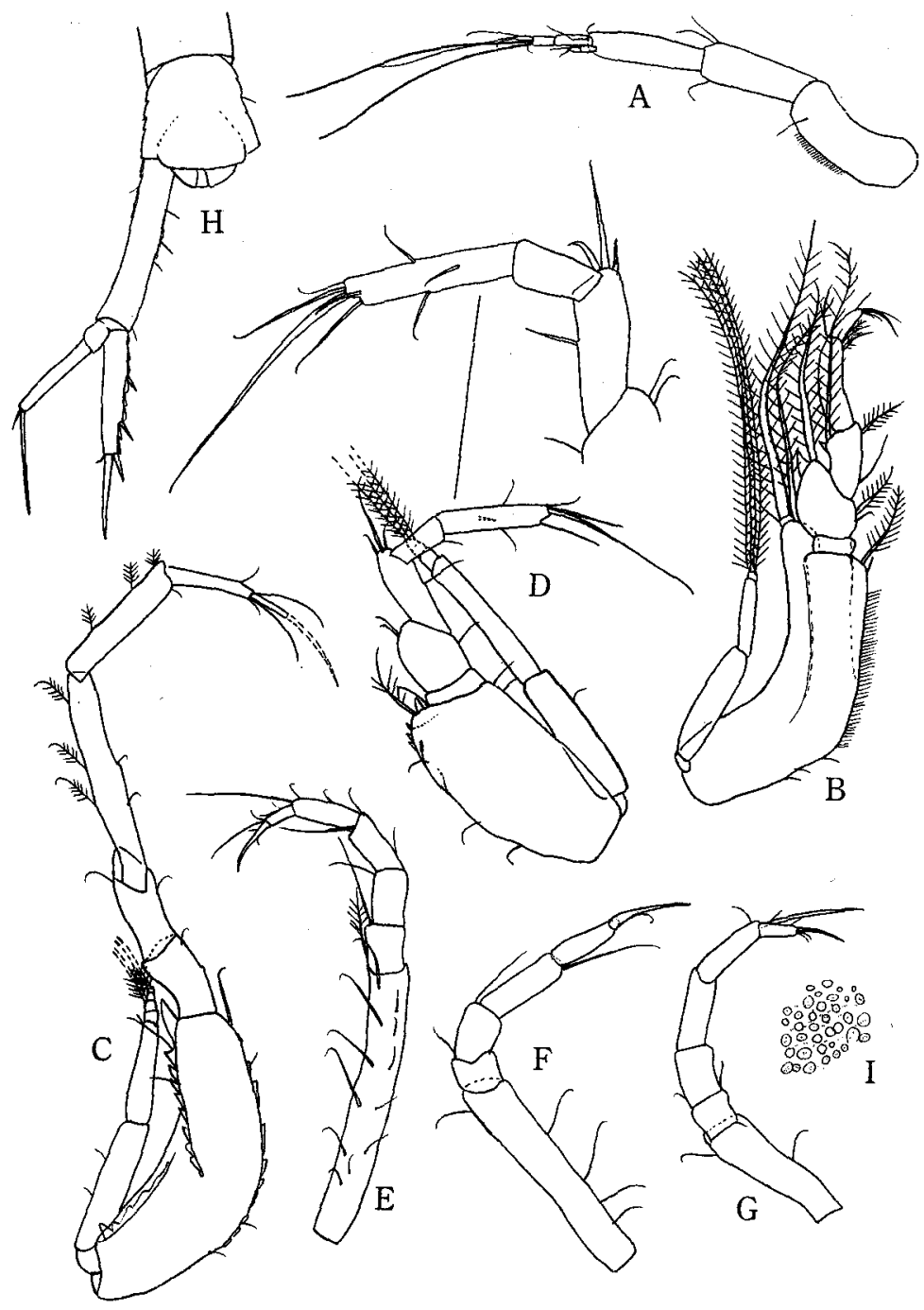

Fig. 31. Cumella arguta sp. nov,, type female. A : antennule. B : third maxilliped. $C-G$ : first to fifth peraeopods. $H$ : uropod with sixth abdominal segment. I : sculpture of carapace.

tooth on each external angle are subequal in length. The propodus is longer than the carpus. The dactylus is slightly less than one-half as long as the propodus.

The basis of first peraeopod is much more than one-half as long as the 
remaining distal joints together and furnished with crests of flat spines on the outer edge and serrated on the inner. The ischium is shorter than the merus, which is one-half as long as the carpus. The propodus is nearly two-thirds as long as the carpus and about one and one-half times as long as the dactylus.

The second peraeopod with an exopod is nearly three-fifths as long as the first. The basis is roubust and about three-fourths as long as the remaining distal joints together. The ischium is distinct. The carpus is about one and one-third times as long as the merus, and twice as long as the propodus. The dactylus is nearly twice as long as the propodus and furnished with terminal setae, of which the longest is much exceeding the length of the joint.

The basis of third and fourth peraeopod without an exopod is nearly as long as the remaining distal joints together. The basis of fifth peraeopod is one-half as long as the remaining distal joints together and the carpus is as long as the propodus.

The peduncle of uropod is one and one-half times as long as the last abdominal segment, slightly less than one and one-half times as long as the endopod and faintly serrated on both lateral edges. The exopod is slightly shorter than the endopod and furnished with a terminal spine, which is just reaching the level of the terminal spine of the endopod. The endopod is provided with serrations and two spines on the inner border and with two terminal spines (of which the longest is about two-thirds as long as the ramus).

Remarks: The new species resembles the female of $C$. forficula CALMAN and C. hispida Calman (Calman '11; Hale '45).

Those differ from the new species as follows: $C$. forficula has the very short uropod; in C. hispida the antero-lateral angle of carapace is rounded and obtuse, the peduncle of uropod is shorter than the last abdominal segment.

Occurrence: $11 \%$ and $2 \%$ (ovigerous, $1 \%$, type specimen).

\section{Cumella sp.}

(Figs. 32, 33)

Juvenile male specimen (length, about $1.4 \mathrm{~mm}$ ): The integument is rather thin. The basis of third maxillped is about as long as the remaining distal joints togetaer. The basis of first peraeopod without a row of flattened spines is threefifths as long as the remaining distal joints together. The carpus is nearly one and one-half times as long as the propodus, which is about twice as long as the dactylus. The basis of second peraeopod with flattened spines is two-thirds as long as the remaining distal joints together. The basis of third and fourth peraeopods with undeveloped exopods is not expanded. The peduncle of uropod is slightly longer than the fifth abdominal segment and serrated on the distal inner edge. The endopod is shorter than the peduncle and furnished with two spines interspersed with serrations on the inner edge and two unequal terminal spines. 


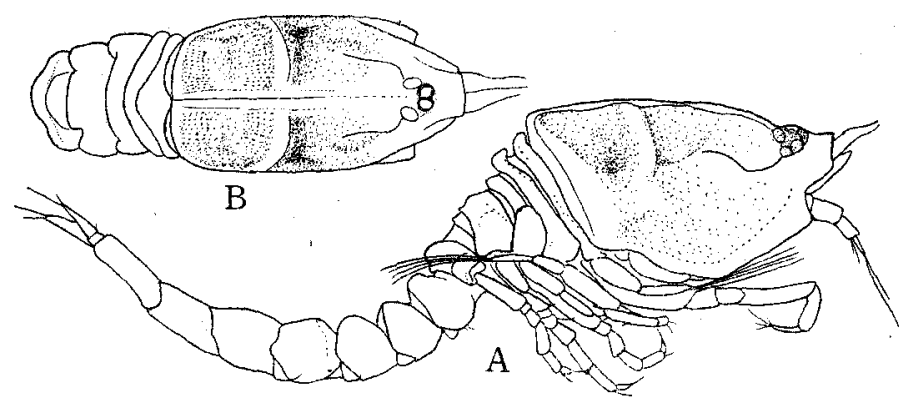

Fig. 32. Cumella sp., juvenile male (length, ca. $1.4 \mathrm{~mm}$ ). A : lateral view. $B$ : anterior portion of body from above.

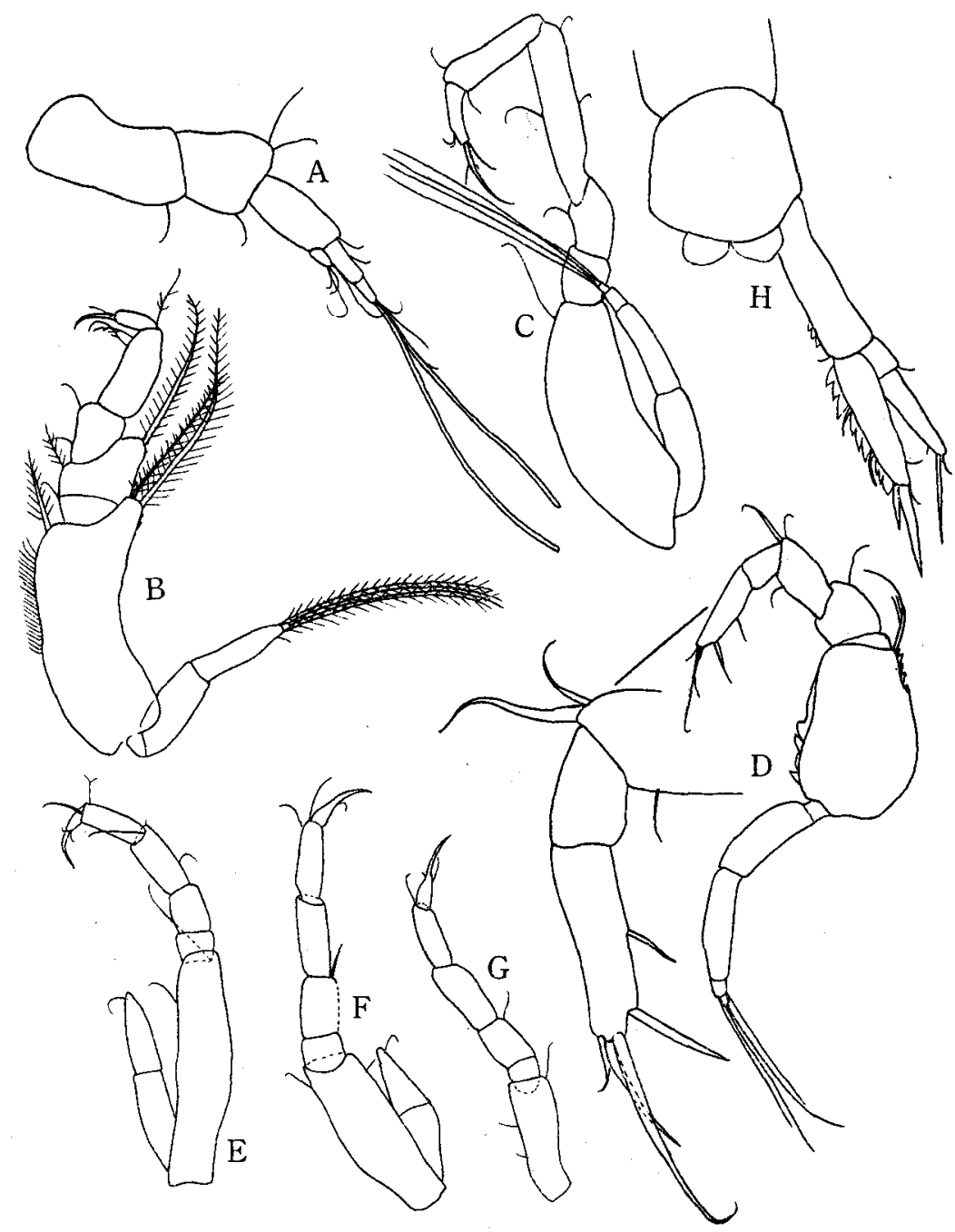

Fig. 33. Cumella sp., juvenile male. A : antenule. B : third maxilliped. $\mathrm{C}-\mathrm{G}$ : first to fifth peraeopods. $\mathrm{H}$ : uropod with sixth abdominal segment. 
The exopod is subequal to the endopod and furnished with a long terminal spine as long as the longer spine of the endopod.

Exact identification of the species could not be made since the specimen is only a single juvenile male. It may be related to $C$. vulgaris HART from Alaska (HART '30; ZimMER '43).

Occurrence: 1 juvenile ${ }^{3}$.

\section{Family Lmpropidae}

\section{Hemilamprops californica ZIMMER}

(Fig. 34)

Hemilamprops (?) californica ZIMMER (1936) p. 429, fig. 36.

Lampropoides californicus, HARADA (1959) p. 240, fig. 6 .
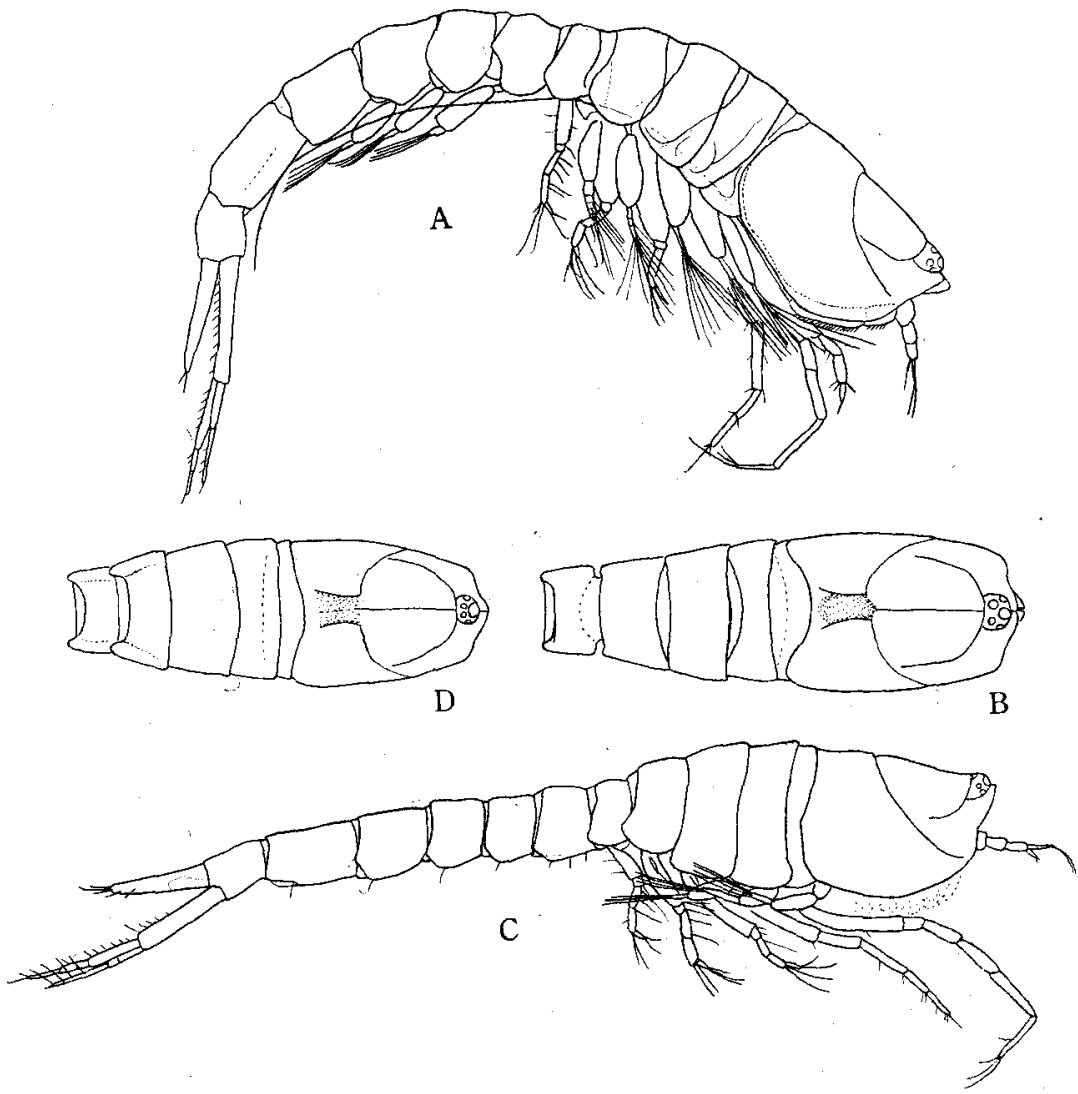

Fig. 34. Hemilamprops californica ZIMMer. Adult male (length, ca. $3.9 \mathrm{~mm}$ ). A : lateral view. B : anterior portion of body, from above. Female (length, ca. $2.9 \mathrm{~mm}$ ). C : lateral view. D : anterior portion of body, from above. 
This species was placed in a new genus Lampropoides which was established by HARADA ('59) based on the following two characters: 1) proportional length of the joints of the outer ramus of the uropod, and 2) number of terminal or lateral spines of the telson.

It seems to me that the differences of the above-mentioned characters are inadequate to separate the new genus Lampropoides from the genus Hemilamprops. The following four species, Lampropoides californicus (ZIMMER) (= Hemilamprops (?) californica ZIMMER), L. diversus (HALE), L. japonicus HARADA and L. pacificus HARADA may be referred to the genus Hemilamprops.

Occurrence: 1ㅎ, 2 우 (1우: young).

Distribution: California; Sagami Bay.

\section{Family Diastylidae}

\section{Dimorphostylis asiatica ZIMMER}

Dimorphostylis asiatica ZIMMER (1921) s. 144, Abb. 45-47.

D. asiatica, FAGE (1945) p. 220, fig. 43.

D. asiatica, LoMAKINA (1955) p. 153 ; (1958a) p. 211 ; (1958b) p. 169, fig. 100.

D. asiatica, GAMÔ (1960a) p. 387 ; $(1960 \mathrm{c})$ p. 118 , pl. 59 , fig. 9 .

D. asiatica, HARADA (1960) p. 203, fig. 2.

Occurrence: $268 \hat{\text { s. }}$.

Distribution: Bay of Peter the Great, Shikotan Island (Southern Kuril); Sagami Bay; Inlet waters of Izu Peninsula, Kochi, Tamano (Okayam) (HaradA '60) ; Nagasaki ; Formosa, Vietnam.

\section{Dimorphostylis quadriplicata GAMô}

Dimorphostylis quadriplicata GAMÔ (1960a) pp. 160, 110, fig. 7.

D. tagoensis HARADA (1960) p. 214 , fig. 7.

Occurrence: $7 \hat{\delta}, 7 \wp$.

Distribution: Sagami Bay, Izu Peninsula.

\section{Dimorphostylis hirsuta GAMÔ}

Dimorphostylis hirsuta GAMÔ (1960a) pp. 107, 111, fig. 8.

D. exigua HARADA (1960) p. 207, fig. 4.

Occurrence: 19 ণ 47 \% (7\%, ovigerous).

Distribution: Sagami Bay, Izu Peninsula.

22. Dimorphostylis longicauda sp. nov.

(Figs. 35, 36) 
Type female specimen (length, about $2.6 \mathrm{~mm}$ ): The carapace is nearly onethird of the total length of animal and about one and one-third times as long as the width, which is as wide as the depth. Three oblique folds are on the lateral portion. On the anterior parts there are small scattered spines and two folds with spinules. The antennal notch is shallowly concave. The rounded anterolateral angle, like the lower margin of the carapace, is faintly serrated. The pseudorostral lobes are meeting for a distance equal to about one-fifth of the length of carapace. The ocular lobe is twice as wide as the length and beset with three eyes.

The first joint of peduncle of antennule is much shorter than the second and third combined. The second is a little more than one-half as long as the third. The main flagellum is two-jointed. The accessory flagellnm is three-jointed and two-thirds as long as the main flagellum.

The basis of third maxilliped is one and one-sixth times as long as the remaining distal joints together and provided with a smaller exopod. There is a

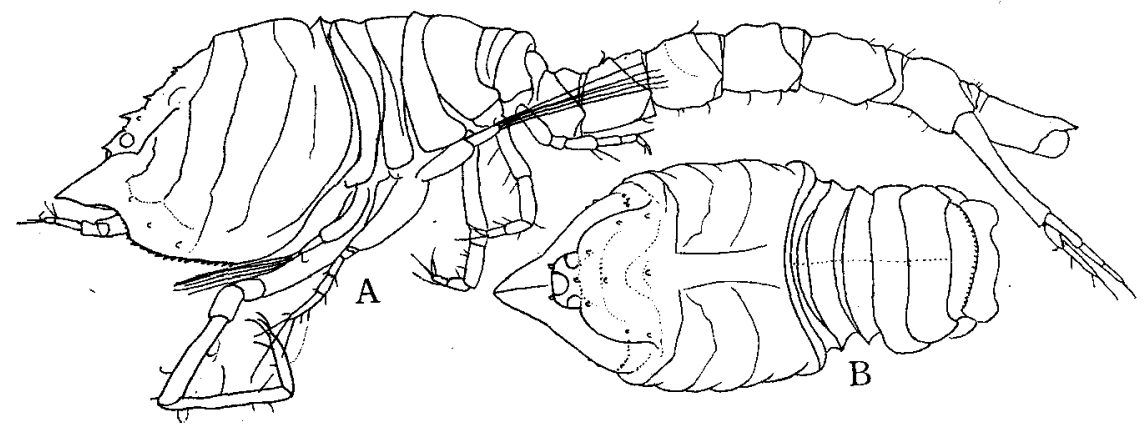

Fig. 35. Dimorphostylis longicauda sp. nov., type female (length, ca. $2.6 \mathrm{~mm}$ ). lateral view. B : anterior portion of body, from above.

tooth on each distal inner angle of basis, ischium and merus.

The basis of first peraeopod is more than one-half as long as the remaining distal joints together. The propodus is much longer than the carpus and merus combined. The dactylus is a little more than one-half as long as the propodus.

The basis of second peraeopod is nearly as long as the remaining distal joints together. The ischium is distinct. The carpus is longer than the merus, and about two-thirds as long as the dactylus. The dactylus has terminal long setae, one of which is much exceeding the length of the joint.

The basis of third and fourth peraeopod without an exopod is more than one-half as long as the remaining distal joints together. The basis of fifth peraeopod is less than one-half as long as the remaining distal joints together.

The peduncle of uropod is one and one-third times as long as the last abdominal segment and furnished with five spines on the inner edge and five hairs on the outer. The exopod is three-fourths as long as the peduncle and longer than the combined length of the first two joints of endopod. The first joint of 


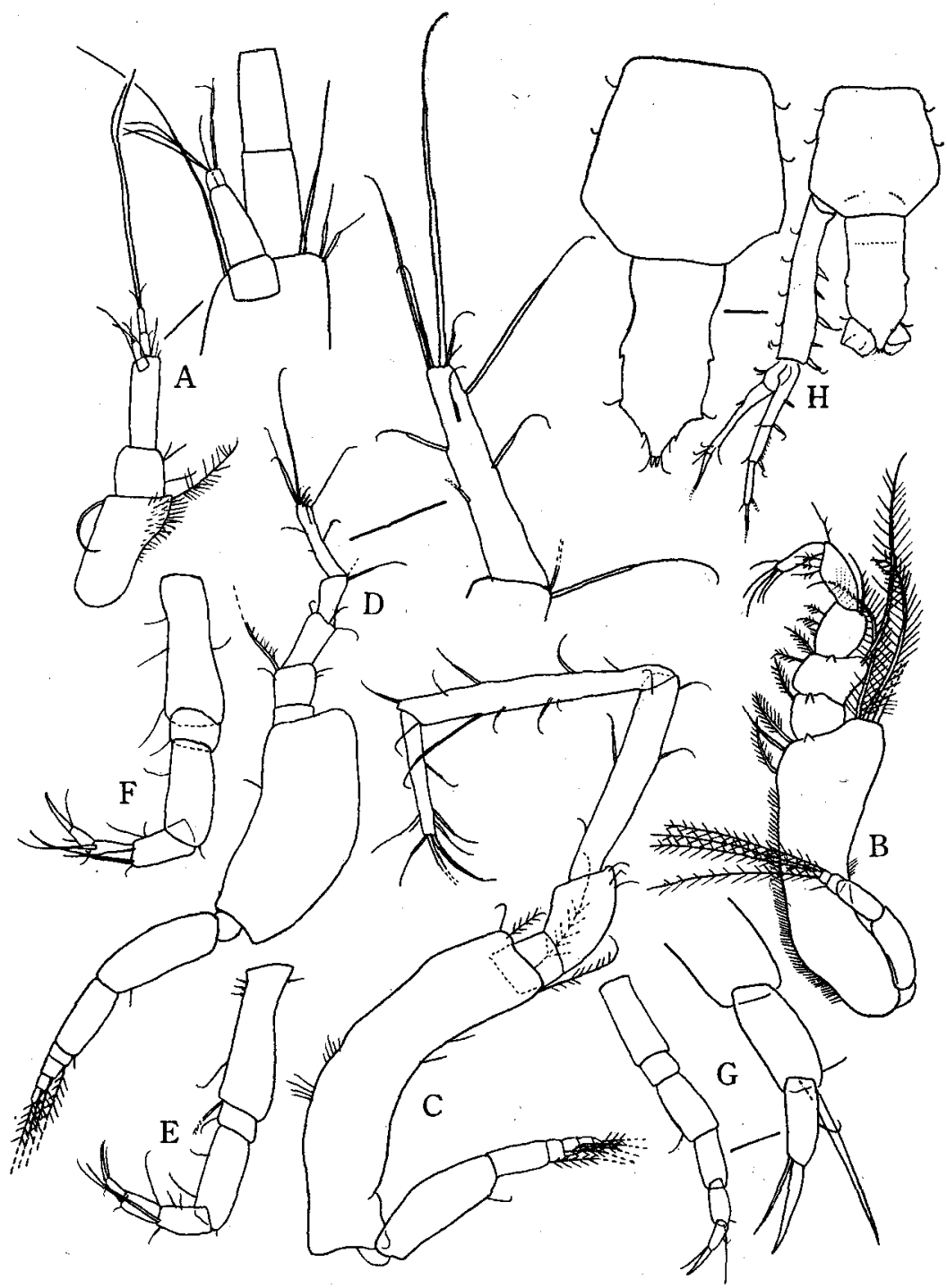

Fig. 36. Dimorphostylis longicauda sp. nov., type female. A : antennule. B : third maxilliped. C-G : first to fifth peraeopods. $H$ : uropod with sixth $a b-$ dominal segment and telson. 
endopod is shorter than the distal two joints combined. The second is shorter than the third. The telson is relatively large, about as long as the last abdominal segment and one-half as wide as its length.

Occurrence: 2 ㅇ ( 1 ㅇ: type specimen).

\section{Dimorphostylis echinata sp. nov.}

(Figs. 37, 38)

Type young female specimen (length, about $2.4 \mathrm{~mm}$ ): The carapace is plump, a little more than one-third of the total length of animal and one and one-half times as long as the width, which is as wide as the depth. Strong spines are scattered on the dorso-median portion and around the frontal lobe. On each side of carapace there are oblique three folds. The anterior portion of the anterolateral fold with spines. The antennal notch is shallowly concave. The anterolateral angle is rounded and, like the lower margin of carapace, furnished with conspicuous serrations. The pseudorostral lobes are meeting for a distance about equal to one-fourth of the length of carapace. The ocular lobe is about as wide as the length.

The first joint of peduncle of antennule is about as long as the second and third combined. The second is much shorter than the third. The main flagellum is nearly two-thirds as long as the third joint of peduncle and four-jointed. The proximal two joints are long and stout and the distal two are minute. The accessory flagellum is about two-thirds as long as the main flagellum and threejointed.

The basis of third maxilliped with a small exopod is much longer than the remaining distal joints together. There is a tooth on each distal inner angle of basis and ischium.

The basis of first peraeopod is much less than one-half as long as the remaining distal joints together. There are two or three strong spines on each distal end of basis, ischium and merus. The propodus is less than as long as the carpus and merus combined. The dactylus is one-half as long as the propodus.

The basis of second peraeopod is stout and shorter than the remaining distal joints together. The ischium is distinct. The carpus is nearly one and one-half times as long as the merus, and much longer than the propodus. The dactylus is one and one-half times as long as the propodus and furnished with long setae, of which the longest terminal ones are much exceeding the length of the dactylus.

The third to fifth peraeopods have no exopods. The basis of third is cylindrical and three-fourths as long as the remaining distal joints together. The carpus is stout and two-thirds as long as the basis. The basis of fourth is short and slightly more than one-half as long as the remaining distal joints together. The carpus is shorter than the basis. The basis of fifth peraeopod is less than onehalf as long as the remaining distal joints together.

$$
-59-
$$


The last abdominal segment is wider than the length and beset with a crest of small spines on the postero-lateral edge, just above the proximal portion of the uropod.

The peduncle of uropod is a little longer than one and one-half times as long as the last abdominal segment and furnished with four spines on the inner edge and five hairs on the outer. The exopod is about two-thirds as long as the

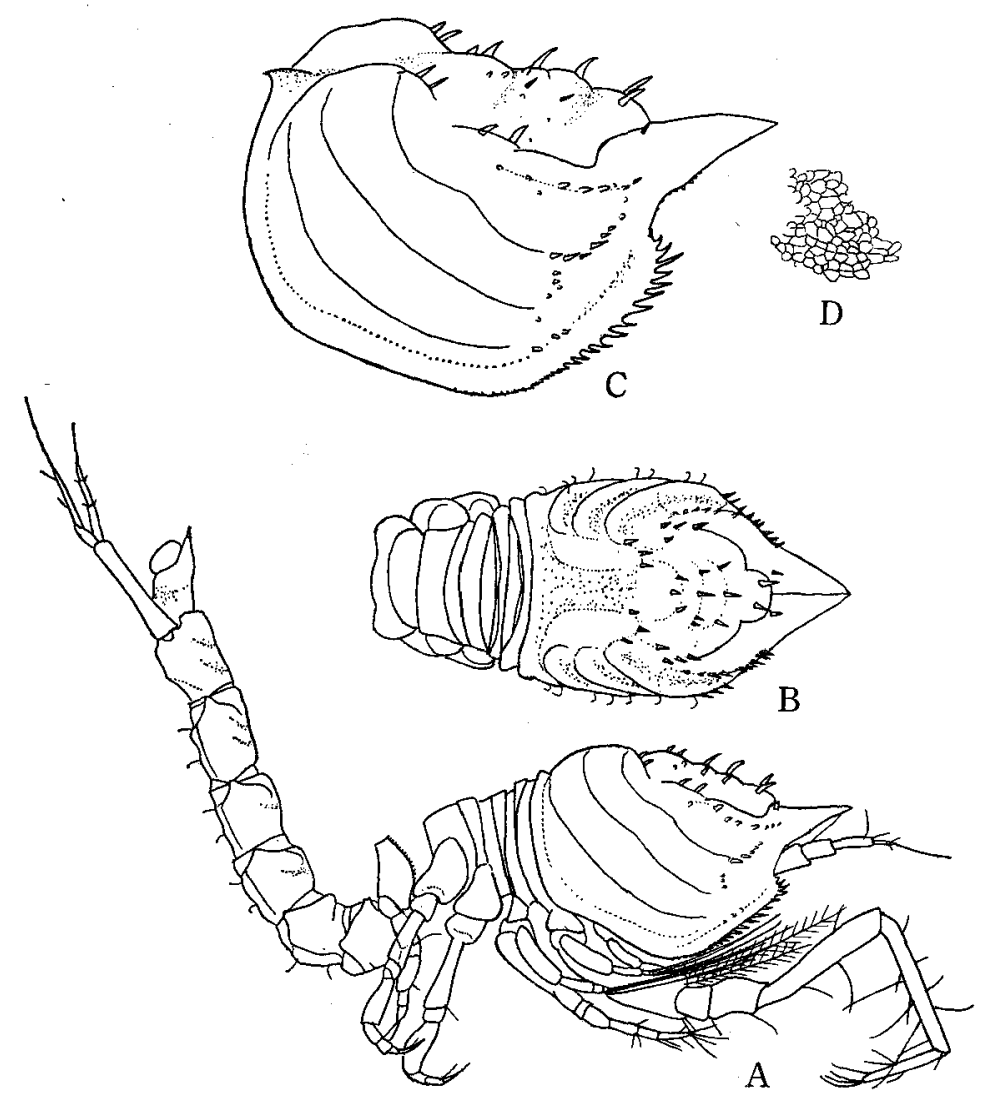

Fig. 37. Dimorphostylis echinata sp. nov., type young female (length, ca. $2.4 \mathrm{~mm}$ ). A : lateral view. B : anterior portion of body, from above. C : carapace, lateral view. D : sculpture of carapace.

peduncle, nearly as long as the endopod and furnished with a long terminal setae. The first joint of endopod is about two-thirds as long as the subequal distal two joints combined. The telson is a little shorter than the last abdominal segment and less than one-half as wide as the length. The lateral sides of the proximal portion are somewhat swollen and a little spinulous. The postanal portion has three pairs of lateral small teeth, and two spinules and two hairs on the distal end. 


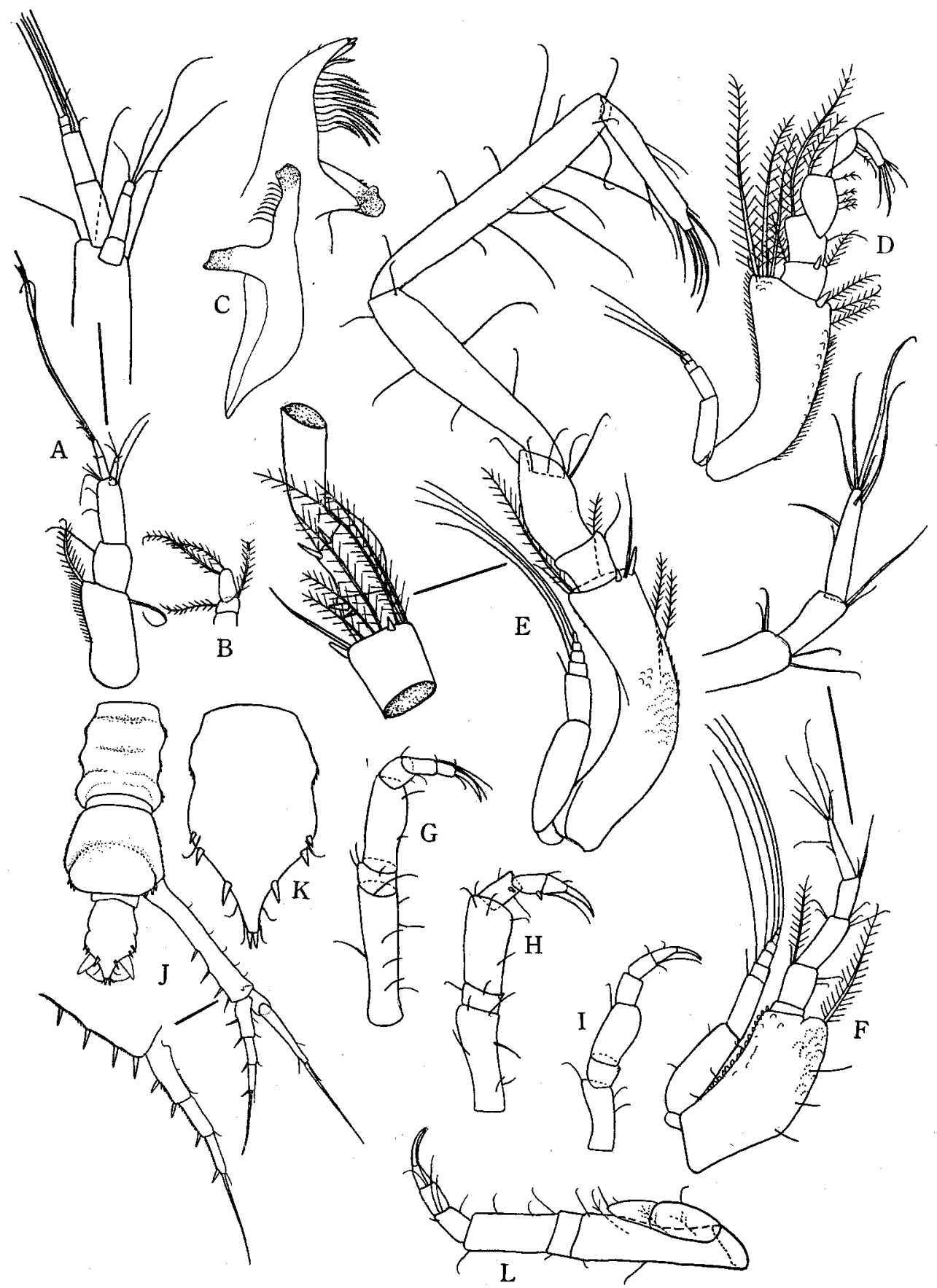

Fig. 38. Dimorphostylis echinata sp. nov., type young female. A : antennule. B : antenna. $\mathrm{C}:$ mandible. D : third maxilliped. E-I : first to fifth peraeopods. J : uropod with fifth and sixth abdominal segments and telson. $\mathrm{K}$ : telson. Paratype young male (length, ca. $2.5 \mathrm{~mm}$ ) : L : third peraeopod. 
Paratype young male (length, about $2.5 \mathrm{~mm}$ ): The young male specimen is very like the young female. The carapace is nearly one and one-third times as long as the width, which is less than as wide as the depth. The third joint of peduncle of antennule is stouter than that of the female. The basis of third to fourth peraeopods with an undeveloped exopod is a little stouter than that of the female. The telson is about as long as the last abdominal segment.

Remarks: The new species resembles very closely D. tasmanica Hale (HALE '45) from Tasmania, from which it is easily distinguished in the shape of the telson.

Occurrence: 2 우 (young, 1 o : type specimen), $10^{\text {T }}$ (young).

\section{Gynodiastylis costatus CALMAN}

(Figs. 39, 40)

Gynodiastylis costata CALMAN (1911) p. 372, pl. 36, figs, 1-10.

G. costatus, Stebbing (1913) p. 163.

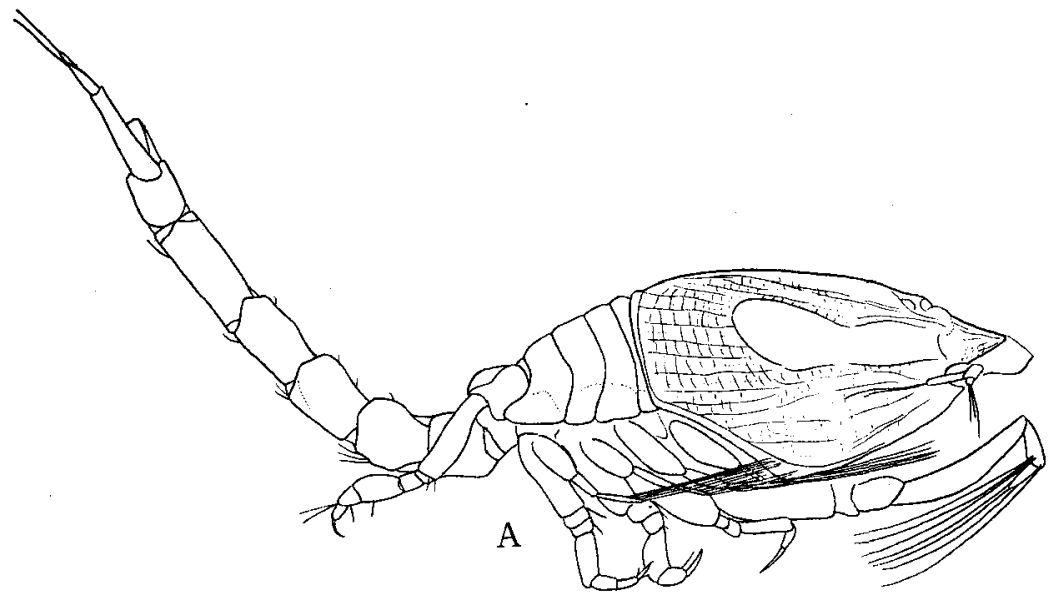

Fig. 39. Gynodiastylis costatus CALMAN. Male (length, ca. $1.7 \mathrm{~mm}$ ). A : lateral view.

Young male specimen (length, about $1.7 \mathrm{~mm}$ ): The carapce is fully threeeighths of the total length of animal, more than twice as long as the free thoracic segments together and about one and three-fourths times as long as the depth, which is four-fifths as deep as the width. There are numerous clear longitudinal and faint transversal ridges and a large, shallow depression on each side. The pseudorostral lobes are damaged and not fully observed from dorsal view. The antennal notch is deeply concave. The antero-lateral angle is subacute. The ocular lobe is as long as the width and furnished with three eyes.

The first free thoracic segment is exporsed dorsally and laterally.

The bdomen is nearly five-sixths as long as the cephalothorax and much less 
than one-half as long as the total length of animal. The fifth abdominal segment is more than one and one-half times as long as the sixth, which is less than one and one-half times as wide as its length. As seen from above the telson is sub-

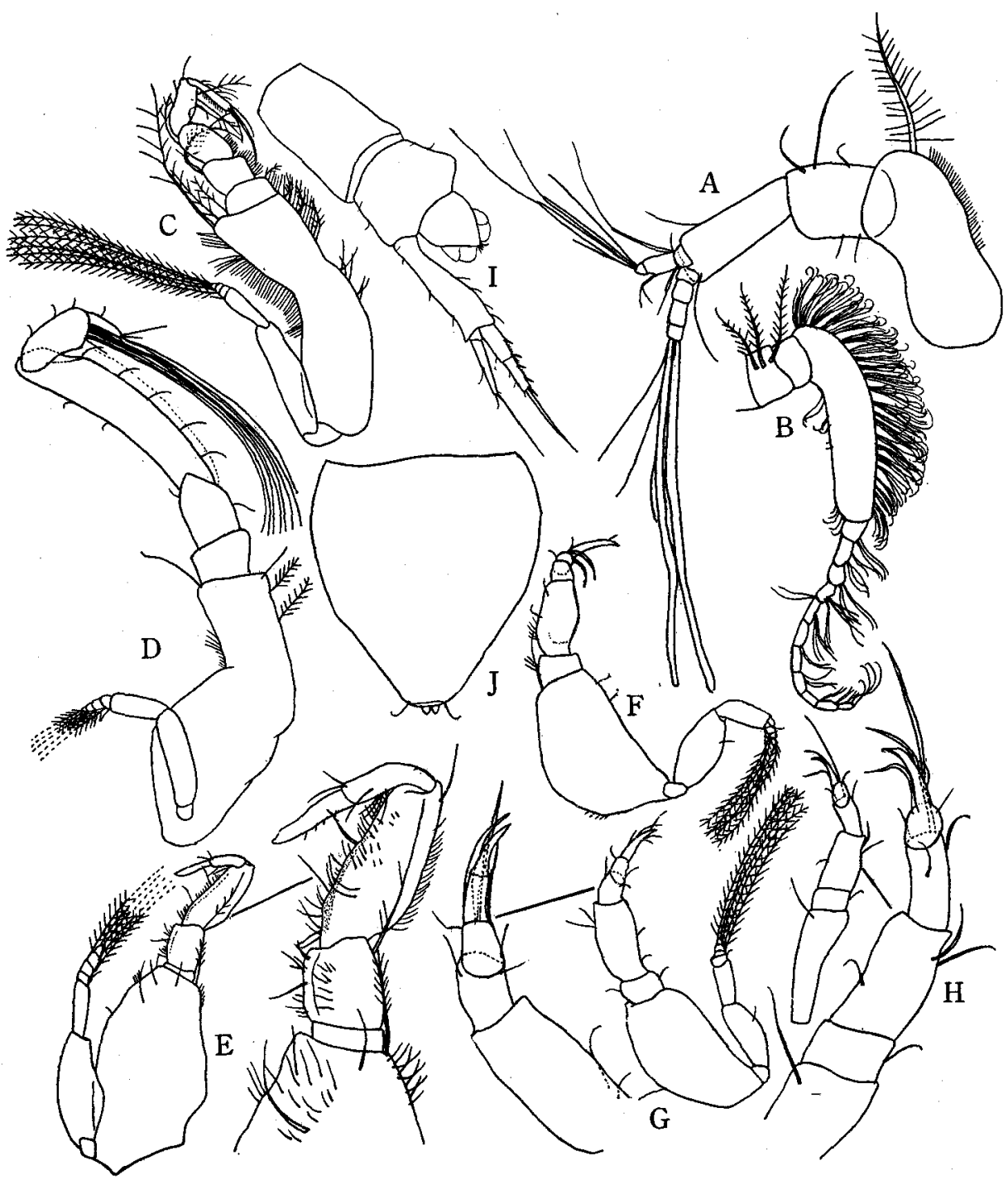

Fig. 40. Gynodiastylis costatus CALMAN. Male. A. antennule. B : antenna. C : third maxilliped. $\mathrm{D}-\mathrm{H}$ : first to fifth peraeopods. I : uropod with fifth and sixth abdominal segments and telson. $\mathrm{J}$ : telson.

triangular in shape and much less than as long as the sixth, both lateral edges are slightly rounded and furnished with small spines and two short setae on the distal end. 
The first joint of peduncle of antennule is about twice as long as the second. The third is less than two-thirds as long as the first. The main flagellum is four-jointed and one and one-third times as long as the accessory flagellum, which is three-jointed.

The flagellum of antenna is about as long as the peduncle.

The basis of third maxilliped is narrow, less than one-third as wide as the length, and about one and one-fourth times as long as the remaining distal joints together. The ischium is shorter than the merus, which is two-thirds as long as the carpus. The dactylus is slightly shorter than the propodus or the carpus.

The basis of first peraeopod is two-thirds as long as the remaining distal joints together. The merus is one and one-half times as long as the ischium. The carpus is long, nearly twice as long as the combined length of ischium and merus, and one-fifth as wide as itself. On the inner edge there is a menbraneous lamella for the whole length and provided with five setae. The propodus is about one-third as long as the carpus and a little narrower than the carpus and furnished with about eight subequal setae on the distal portion. The dactylus is slender, nearly one-half as long as the propodus and furnished with distal setae, one of which is as long as the propodus.

The basis of second peraeopod is stout and as long as the remaining distal joints together. The ischium is very short. The merus is one-half as long as the carpus. The carpus is one-third as wide as the length and hairy on both lateral edges. The dactylus is cylindrical and as long as the propodus, which is twofifths as long as the carpus.

The last abdominal segment is less than two-thirds as long as the fifth and one and one-third times as wide as itself. The telson is subtriangular, four-fifths as long as the last abdominal segment and furnished with a pair of short hairs and two spinules on the distal end. The peduncle of uropod is stout, twice as long as the telson and furnished with four setae on the inner edge. The endopod is two-jointed, nearly two-thirds as long as the peduncle and furnished with spinules and spaced four spines on the inner edge and a long terminal spine. The exopod is slightly shorter than the endopod and furnished with a long terminal spine.

Remarks : This specimen may be referred to G. costatus CALMAN (CALMAN '11) from Gulf of Siam by having the carapace with numerous ridges and antero-lateral shallow depression, and in the relative length of the joints of the uropod and in other general features.

Occurrence: $10^{7}$ (immature).

Distribution: Gulf of Siam. 


\section{LITERATURE}

BĂCescu, M. 1951. Cumacea, Fauna Republicii Populare Rômane. vol. IV, fasc. 1, pp. 1-91, figs. 1-194. Bucharest.

Calman, W. T. 1904. Report on the Cumacea collected by Prof. Herdman, at Ceylon, in 1902. Ceylon Pearl Oyster Fish., 1904, Suppl. Rep., xii, pp. 159-180, pls. 1-5. 1905a. The Marine Fauna of the West Coast of Ireland, part v. Cumacea. Sci. Invest. Fish. Ireland, 1904, app. 1, pp. 3-52, pls. 1-5. 1905b. The Cumacea of the Siboga Expedition. Siboga Expeditie, monogr. 36 pp. 1-23, pls 1-2, figs. 1-4.

1907. On new or rare Crustacea of the Order Cumacea from the Collection of the Copenhagen Museum. Part I. The Families Bodotriidae, Vaunthompsoniidae, and Leuconidae. Trans. Zool. Soc., London. vol. 18, pp. 1-58, pls. 1-9.

1911. On new or rare Crustacea of the Order Cumacea from the Collection of the Copenhagen Museum, Part II. The Families Nannastacidae and Diastylidae. Ibid., vol. 18, pp. 341-385, pls. 32-37.

1912. The Crustacea of the order Cumacea in the collection of the United States

National Museum. Proc. U.S. Nat. Mus., vol. 41, pp. 603-676, figs. 1-112.

FAGE, L. 1945. Les Cumacés du plankton nocturne des côtes d'Annam. Arch. Zool. éxp. et gén., T. 84, pp. 165-223, figs. 1-43.

1951. Les Cumacés. Faune de France. T. 54, pp. 1-136, figs. 1-109. Paris.

GAMô, S. 1958. On some species of Cumacean Crustacea from Sagami Bay. Zool. Mag., vol. 67, pp. 383-369, figs. $1-2$.

1960a. Five new species of cumacean Crustacea, Genus Dimorphostylis (Diastylidae) from Sagami Bay. Ibid., vol. 69, pp. 101-111, figs. 1-8.

1960b. On three new species of cumacean Crustacea Genus Campylaspis from Tanabe

Bay, Kii Penisula. Publ. Seto Mar. Biol. Lab., vol. 8, no. 1, pp. 153-161, figs. 1-6.

- 1960c. Cumacea. Encyclopedia Zoologica Illustrated in Colours. vol. IV, p. 118, pl. 59. (pp. 1-246, pls. 1-123) Tokyo. (in Japanese).

Hale, H. M. 1945a. Australian Cumacea. No. 9. The Family Nannastacidae. Rec. S. Aust. Mus., vol. 8, pp. 145-218, figs. 1-49.

1945b. Australian Cumacea. No. 11. The Family Diastylidae (Part I). Trans. Roy.

Soc. S. A., vol. 69 , pp. 173-211, figs. 1-26.

1948. Australian Cumacea. No. 14. Futher notes on the Genus Cyclaspis. Rec. S. Aust. Mus., vol. 9, pp. 1-42, figs. 1-21.

HARADA, I. 1959. Cumacean Fauna of Japan I. Family Lampropidae. Jap. Journ. Zool., vol. 12, pp. 229-246, figs. 1-7.

1960. Cumacean Fauna of Japan II. Family Diastylidae (Part 1). Genus Dimorphos-

tylis. Sci. Rep. Tokyo Kyoiku Daigaku, section B, 9, pp. 199-225, figs. 1-12.

HART, J. F. L. 1930. Some Cumacea of Vancouver Island region. Contr. Canada. Biol. Tronto, vol. 6 , pp. $23-40$, figs. $1-5$.

Kurian, C. V. 1951. The Cumacea of Trivancore. Bull. Central Res. Inst., Univ. Travancore. ser. C. II, pp. 77-118, pls. 1-4.

1954. Notes on Cumacea (Sympoda) in the Zoologifal Survey of India. Rec. Indian Mus., vol. 52, pp. 275-311, figs. 1-14.

Lomakina, N. B. 1952. New species of Cumacea of Far-East Seas. Trav. Inst. Zool. Acad. Sci. U. S. S. R., T. 12, pp. 115-170, figs. 1-24. (In Russian)

Russian)

1955. Cumacea from Far-East Seas. Ibid., T. 18, pp. 112-165, figs. 1-15. (In

1958a. Cumacea of the region of the Kuril-Sakhalin expedition warks. Explor.

Far Eastern Seas of U. S. S. R., T. 5, pp. 205-216, figs. 1-2. (In Russian) 
Lomakina, N. B. 1958b. Cumacea of the Seas of U. S. S. R., pp. 1-301, figs. 1-201. Moscow. (In Russian)

SARS, G. O. 1878-1879. Ney Bidrag til Kundskaben om Middlhavets Invertebratfauna. II. Middelhavts Cumaceer. Arch. Math. Naturv., T. 3-4, pp. 1-196, Tafs. 1-60. 1887. Report on the Cumacea collected by $H$. M. S. Challenger during the years 1873-1876. Rep. Voy. Challenger, Part 55, pp. 1-78, pls. 1-11. 1900. An account of the Crustacea of Norway, III. Cumacea. pp. i-x, 1-114, Tafs. 1-69. Christiania.

Stebbing, Th. R. R. 1900. On Crustacea brought by Dr. Willey from the South Sea. Zoological Resalts based on material from New Britain, New Guinea, Loyality Island and elsewhere collected during the year 1895,1897 by Dr. Willey, Pt. V, pp. 605-690, pls. 44-74.

1-137. Berlin. 1913. Cumacea (Sympoda). Das Tierreich. Lief. 39, pp. i-xvi, 1-210, figs.

ZrMmer, C. 1913. Die Cumaceen der Deutchen Südpolar-Expedition 1901-1903. Dtch. Südp.-Exp., Bd. 14 , s. $473-492$, Tafs. $40-47$, Abb. 1-2. 1914. Fauna Suidwest Aust., V. Cumacea. s. 175-195, Abb. 1-18. 1921. Mitteilungen über Cumaceen des Berliner zoologischen Museums. Mitt. Zool. Mus. Berlin. Bd. 10, s. 117-149, Abb. 1-55. 1936. California Crustacea of the Order Cumacea. Proc. U. S. Nat. Mus., vol. 83, pp. $423-439$, figs. $1-39$.

_ 1943. Cumaceen des Stillen Ozeans. Arch. f. Naturgesch., Bd. 12, s. 130-439, Abb. $1-61$. 1944. Cumaceen des tropischen Westatlantiks. Zool. Anz., Bd. 144, s. 121-137, Abb. $1-30$. 1952. Indochinesische Cumaceen. Mitt. Zool. Mus. Berlin. Bd. 28, s. 5-35, Abb. 1-50. 